\title{
Metabolomics and Ionomics of
} Potato Tuber Reveals an Influence of Cultivar and Market Class on Human Nutrients and Bioactive Compounds

\author{
Jacqueline M. Chaparro ${ }^{1,2}$, David G. Holm ${ }^{1}$, Corey D. Broeckling ${ }^{1,2}$, Jessica E. Prenni ${ }^{1,2}$ \\ and Adam L. Heuberger ${ }^{1,3 *}$ \\ ${ }^{1}$ Department of Horticulture and Landscape Architecture, Colorado State University, Fort Collins, CO, United States, \\ 2 Proteomics and Metabolomics Facility, Colorado State University, Fort Collins, CO, United States, ${ }^{3}$ Department of Soil and \\ Crop Sciences, Colorado State University, Fort Collins, CO, United States
}

\section{OPEN ACCESS}

Edited by:

Holger Hintelmann,

Trent University, Canada

Reviewed by:

Susana Casal,

Universidade do Porto, Portugal

Sui Kiat Chang,

International Medical University,

Malaysia

*Correspondence:

Adam L. Heuberger

adam.heuberger@colostate.edu

Specialty section:

This article was submitted to

Food Chemistry,

a section of the journal

Frontiers in Nutrition

Received: 11 January 2018 Accepted: 19 April 2018

Published: 23 May 2018

Citation:

Chaparro JM, Holm DG,

Broeckling $C D$, Prenni JE and Heuberger AL (2018) Metabolomics and Ionomics of Potato Tuber Reveals an Influence of Cultivar and Market

Class on Human Nutrients and Bioactive Compounds.

Front. Nutr. 5:36.

do: 10.3389/fnut.2018.00036
Potato (Solanum tuberosum L.) is an important global food crop that contains phytochemicals with demonstrated effects on human health. Understanding sources of chemical variation of potato tuber can inform breeding for improved health attributes of the cooked food. Here, a comprehensive metabolomics (UPLC- and GC-MS) and ionomics (ICP-MS) analysis of raw and cooked potato tuber was performed on 60 unique potato genotypes that span 5 market classes including russet, red, yellow, chip, and specialty potatoes. The analyses detected 2,656 compounds that included known bioactives (43 compounds), nutrients (42), lipids (76), and 23 metals. Most nutrients and bioactives were partially degraded during cooking (44 out of $85 ; 52 \%$ ), however genotypes with high quantities of bioactives remained highest in the cooked tuber. Chemical variation was influenced by genotype and market class. Specifically, 53\% of all detected compounds from cooked potato varied among market class and $40 \%$ varied by genotype. The most notable metabolite profiles were observed in yellow-flesh potato which had higher levels of carotenoids and specialty potatoes which had the higher levels of chlorogenic acid as compared to the other market classes. Variation in several molecules with known association to health was observed among market classes and included vitamins (e.g., pyridoxal, 2-fold variation), bioactives (e.g., chlorogenic acid, $\sim 40$-fold variation), medicinals (e.g., kukoamines, $\sim 6$-fold variation), and minerals (e.g., calcium, iron, molybdenum, $\sim 2$-fold variation). Furthermore, more metabolite variation was observed within market class than among market class (e.g., $\alpha$-tocopherol, $\sim 1$-fold variation among market class vs. $\sim 3$-fold variation within market class). Taken together, the analysis characterized significant metabolite and mineral variation in raw and cooked potato tuber, and support the potential to breed new cultivars for improved health traits.

Keywords: Solanum tuberosum L., potato, bioactive compounds, nutrients, ionomics, non-targeted metabolomics, human health

\footnotetext{
Abbreviations: $\mathrm{MeOH}$, methanol; MTBE, methyl tert-butyl ether; CV, coefficient of variation; UPLC-MS, ultra-performance liquid chromatography-mass spectrometry; GC-MS, gas chromatography-mass spectrometry; ICP-MS, inductively coupled plasma-mass spectrometry; USDA, United States Department of Agriculture; PCA, principal component analysis; PC, principal component; $\mathrm{mFV}$, mean fold variation; ANOVA, analysis of variance.
} 


\section{INTRODUCTION}

Chronic diseases such as heart disease, diabetes, cancer, and obesity are a global problem, accounting for $2 / 3$ of global mortality, and rates of these conditions have been shown to be twice as high in low/middle income countries (1). The impact of chronic diseases is strongly influenced by lifestyle choices such as exercise and diet (1). While diet may not be a sole or even major component of disease prevention or interception, there is a clear role of nutrients and other bioactive compounds in the initiation, development, and severity of chronic diseases (2-5). This is supported by epidemiological studies that highlight the importance of food, diet, and nutrition to prevent and control development of such diseases (5-7). Plant foods provide two types of compounds with effects on health: nutrients (required for human metabolism and development, such as vitamins and minerals) and bioactive compounds (herein referred to as "bioactives") that have physiological, behavioral, and/or immunological effects but are not known to be essential to sustain life (8-10).

Potato (Solanum tuberosum L.) is an important source of nutrients and bioactives for the global population. It is the third most consumed food crop and diet staple for over one billion people (11). Potatoes are grown in nearly all nations, and production in developing nations equaled the developed world in 2005 (11, 12). The potato tuber contains a diverse set of nutrients and bioactive compounds with clear effects on preventing and combating chronic diseases such as hypertension, cancer, diabetes, and heart disease (13-23). The tuber is a nutrient-dense food, which means that it provides a greater percentage of nutrients than its estimated 100 calories per serving $(12,24,25)$. For example, $100 \mathrm{~g}$ of baked potato (97 calories) contains $15 \%$ of the recommended amounts of vitamin B6, $16 \%$ of potassium, $9 \%$ of magnesium, $6 \%$ of iron, and $4 \%$ of pantothenic acid $(12,26)$. Potato tuber also contains several bioactives including polyphenolics (e.g., chlorogenic acid, methylbelliferones, and the flavonoids apigenin, rutin, and kaempferol 3-O-rutinoside), terpenes (e.g., the carotenoids lutein and neoxanthin), polyamines (e.g., kukoamines), and alkaloids (e.g., calystegines, solanine, tomatine, and chaconine), which have demonstrated activity against cancer (27-32), heart disease $(31,33,34)$, hypertension $(33,35-37)$, diabetes (3842), Parkinson's disease (43), Alzheimer's disease (44, 45), and obesity $(46,47)$. Glycoalkaloids are most commonly found in the Solanaceae family which includes potatoes (48). While toxic in large doses, glycoalkaloids can reduce serum cholesterol and have anticarcinogenic effects (49-52), for example by disrupting cell membranes and modulating calcium ion concentrations (53).

As a plant and food, potato has a vast biodiversity with over 5,000 documented cultivars and more than 100 wild potato species (54). In U.S. potato breeding for commercial production, this biodiversity has enabled the formation of distinct market classes with unique tuber phenotypes. These market classes include: russets (oblong-long shape for baking and frying, used in the fresh and processing markets), reds (oval-round shape for fresh market, higher sugar content), yellows (high carotenoids for yellow internal flesh, fresh market), chips (quality, density and round shape for chip processing), and specialties (non-traditional shapes, mixed colors, heirlooms). Variation within each market class consists of unique cultivars, which are potato genotypes released from breeding programs for commercial use. Additional genetic diversity can be found in potato breeding programs within advanced lines, which are potato genotypes that have undergone selection for critical quality traits, but have not yet been released to the market.

The large genotypic and phenotypic diversity in potato supports the hypothesis that tubers will vary widely in their content of nutrients and bioactives. Previous studies have demonstrated genetic control over nutrients and bioactives in foods such as rice, tomato, and potato (55-59). Studies on diverse potato populations have revealed variation in carotenoids, total phenolics, iron and zinc, chlorogenic acid, caffeic acid, rutin, and kaempferol $(59,60)$. Similar results were obtained in a study that analyzed 25 potato genotypes from the Texas Potato Variety Development Program and found that potato genotype significantly influenced phenolic and carotenoid content (61).

Current research highlights the utility of metabolomics and ionomics as high-throughput methods to profile variation in nutrients and bioactive compounds in foods. In these studies, mass spectrometry is used to profile small molecules (i.e., metabolites $<1,200 \mathrm{Da}$ ) and elements (minerals) (6264). For example, metabolomics and ionomics have been utilized to evaluate diversity in the nutrient content and health traits of plant-based foods for up to 21 minerals and thousands of metabolites in rice, tomato, wheat, ají, cucumber, eggplant, beans, and others (55, 56, 63-69). Several studies have shown an influence of plant genotype on metabolite content of foods, including wheat (phenolics and sterols) (69) and rice (phenolics, tocopherols, phytosterols, fatty acids) (55). Other studies have evaluated how plant genetics lead to differences in mineral content of vegetable crops (essential minerals) (68), rice ( $\mathrm{Ca}, \mathrm{Cu}, \mathrm{K}, \mathrm{Na}, \mathrm{Zn}$ ) (70), maize (71, 72 ), soybean (73), and sorghum (74), were evaluated to identify genetic loci associated to content of up to 19 minerals.

Here, we report variation of nutrients, bioactives, and minerals of 60 distinct potato genotypes that include commonly grown cultivars and advanced breeding lines among five market classes (russets, reds, yellows, chips, and specialty potatoes). Metabolomics and ionomics was utilized to estimate and characterize the quantitative differences among potato market classes, genotypes, and variation within market class and within a genotype on potatoes suited for the commercial market. The effect on cooking was also evaluated to estimate if raw potato chemical content can predict nutrient and bioactive content of the cooked food, which would expedite screening for healthdense cultivars. Taken together, this research highlights the breadth and diversity of metabolites present in a relatively narrow potato gene pool, and lays the groundwork for future breeding efforts to generate potatoes with enhanced qualities for human health. 


\section{MATERIALS AND METHODS}

\section{Potato Tuber Materials for Chemical Analysis}

Potato plants were grown in 2014 in the San Luis Valley, Colorado, USA as part of the Colorado Potato Breeding and Selection Program (http://potatoes.colostate.edu/potatobreeding/) and stored at $4{ }^{\circ} \mathrm{C}$ for 3 months. A total of 60 potato genotypes were selected that span five market classes (russet, red, yellow, chip, and specialty) and represent both commonly grown cultivars and advanced breeding lines (Table 1). Potatoes were rinsed with distilled water and dried. Four potato tubers from each genotype were weighed and half $(n=2)$ were immediately frozen in liquid nitrogen while the other half $(n=2)$ were cooked via microwave as previously described (17). Briefly, the fresh weight of each potato was used to calculate cooking time, where $30 \mathrm{~g}$ of potato fresh weight was cooked for $1.75 \mathrm{~min}$ at $400 \mathrm{~W}$ power. After cooking, potato tubers were immediately frozen in liquid nitrogen. The cooking was chosen based on previous work that demonstrated microwaving results in less degradation of nutrients and bioactives than boiling, baking, and frying $(20,75)$. Raw and cooked frozen tuber samples were shattered using a hammer and freeze-dried. The freeze-dried tubers were coarsely ground with a blender followed by a fine grind in a Wiley ${ }^{\circledR}$ MiniMill (Thomas Scientific, Swedesboro, NJ, USA), with a $0.425 \mathrm{~mm}$ sieve.

\section{Metabolite Extraction}

A biphasic extraction was utilized to optimize the extraction of a wide range of chemical compounds $(62,76,77)$. One milliliter of a cold $\left(-20^{\circ} \mathrm{C}\right)$ biphasic solution [6:3:1; Methyl tert-butyl ether (MTBE): Methanol (MeOH): Water; v:v:v] was added to $100 \mathrm{mg}$ of freeze-dried potato tuber powder in an ice bath, and the samples were vortexed at $4^{\circ} \mathrm{C}$ for $1 \mathrm{~h}$. After $1 \mathrm{~h}, 750 \mu \mathrm{L}$ of cold $\left(4^{\circ} \mathrm{C}\right)$ water was added to induce phase separation. Samples were centrifuged for $25 \mathrm{~min}$ at $2,850 \mathrm{x}$ g at $4^{\circ} \mathrm{C}$. The upper (organic) and lower (aqueous) phases were collected and placed in separate $2 \mathrm{~mL}$ glass vials and stored at $-20^{\circ} \mathrm{C}$.

\section{Metabolite Detection Using Ultra Performance Liquid Chromatography Mass Spectrometry (UPLC-MS)}

For UPLC-MS metabolite analysis, the organic and aqueous extracts were combined $(2: 1, \mathrm{v}: \mathrm{v})$ and dried using a speedvac. UPLC-MS analysis of the aqueous (Supplementary Figure 1A), organic (Supplementary Figure 1B), and a combination of aqueous and organic (Supplementary Figure 1C) revealed that recombining the aqueous and organic fractions in a 2:1 (v:v) ratio resulted in much broader coverage of the potato metabolome. Samples were re-suspended in $100 \mu \mathrm{L}$ of MTBE: MeOH: Water (6:3:1, v:v:v) and $5 \mu \mathrm{L}$ of metabolite extract was injected into an Acquity UPLC system (Waters Corporation). Metabolite separation and detection methods were performed as previously described (78). Separation was performed using an Acquity UPLC CSH Phenyl-Hexyl column $(1.7 \mu \mathrm{m}, 1.0 \times 50 \mathrm{~mm}$; Waters Co.), at a constant flow rate of $200 \mu \mathrm{L} / \mathrm{min}$, using a gradient from solvent A ( $2 \mathrm{mM}$ of ammonium hydroxide, $0.1 \%$ formic acid) to solvent B (acetonitrile, $0.1 \%$ formic acid). Injections were made in $100 \% \mathrm{~A}$ and held for $1 \mathrm{~min}$, a $13 \mathrm{~min}$ linear gradient to $95 \%$ B was then applied, and held at $95 \%$ B for $3 \mathrm{~min}$. The system was returned to starting conditions over $0.05 \mathrm{~min}$ and allowed to re-equilibrate for $3.95 \mathrm{~min}$. The column was held at $65^{\circ} \mathrm{C}$ while samples were held at $6^{\circ} \mathrm{C}$. The column eluent was infused into a Waters G2 ESI-TOF mass spectrometer with an electrospray ion source acquiring in positive ion mode scanning $50-1,200 \mathrm{~m} / \mathrm{z}$ at $0.2 \mathrm{~s}$ per scan, alternating between MS ( $6 \mathrm{~V}$ collision energy) and $\mathrm{MS}^{\mathrm{E}}$ mode (15-30 V ramp). Sodium iodide was used for calibration with $1 \mathrm{ppm}$ mass accuracy. The capillary voltage was held at $2,200 \mathrm{~V}$, source temp at $150^{\circ} \mathrm{C}$, and nitrogen desolvation temperature at $350^{\circ} \mathrm{C}$ with a flow rate of $800 \mathrm{~L} / \mathrm{h}$. Replicate injections of each sample were used as quality control to account for analytical variation.

\section{Metabolite Detection Using Gas Chromatography Mass Spectrometry (GC-MS)}

GC-MS analysis was performed on the aqueous phase of the potato extract. Initial analyses demonstrated the need to utilize different volumes of the aqueous layer for cooked and raw potato due to the GC-MS inlet, column, and/or detector saturating due to excess saccharides in cooked potato. Specifically, $150 \mu \mathrm{L}$ (raw potato) or $75 \mu \mathrm{L}$ (cooked) of aqueous phase extract was transferred to a new tube and dried using a speedvac. Derivatization (methoximation and silylation) and GC-MS detection was performed as previously described (78). Briefly, $50 \mu \mathrm{L}$ of pyridine containing $15 \mathrm{mg} / \mathrm{mL}$ of methoxyamine hydrochloride was added and samples were incubated for $45 \mathrm{~min}$ at $60^{\circ} \mathrm{C}$, sonicated for $10 \mathrm{~min}$, and incubated again for $45 \mathrm{~min}$ at $60^{\circ} \mathrm{C}$. Subsequently, $50 \mu \mathrm{L}$ of N-Methyl-M-(trimethylsilyl) trifluoroacetamide (MSTFA) + $1 \%$ trimethylchlorosilane (TMCS) (ThermoFisher Scientific, Waltham, MA, USA) was added and samples were incubated at $60^{\circ} \mathrm{C}$ for $30 \mathrm{~min}$. Samples were centrifuged at $2,850 \mathrm{x} \mathrm{g}$ at $4^{\circ} \mathrm{C}$, and $80 \mu \mathrm{L}$ of the supernatant was transferred to a $150 \mu \mathrm{L}$ glass insert. GC-MS was performed using a Trace GC Ultra coupled to a Thermo DSQ II (Thermo Scientific, Waltham, MA, USA. Metabolites were separated with a $30 \mathrm{~m}$ TG-5MS column (Thermo Scientific, $0.25 \mathrm{~mm}$ i.d. $0.25 \mu \mathrm{m}$ film thickness). The program began at $80^{\circ} \mathrm{C}$ for $30 \mathrm{~s}$, ramped to $330^{\circ} \mathrm{C}$ at a rate of $15^{\circ} \mathrm{C}$ per min, and ended with an $8 \mathrm{~min}$ hold at a $1.2 \mathrm{~mL} / \mathrm{min}$ helium gas flow rate. Masses between 50 and $650 \mathrm{~m} / \mathrm{z}$ were scanned at five scans/s after electron impact ionization. The inlet temperature was held at $280^{\circ} \mathrm{C}$ and the auxiliary line was held at $300^{\circ} \mathrm{C}$. Replicate injections of each sample were used as quality control to account for analytical variation.

\section{Metabolomics Data Processing}

UPLC- and GC-MS files were converted to .cdf format and each set was independently processed by XCMS $(79,80)$ in R (81). Samples were normalized to total ion current and relative abundance for each molecular feature was determined 


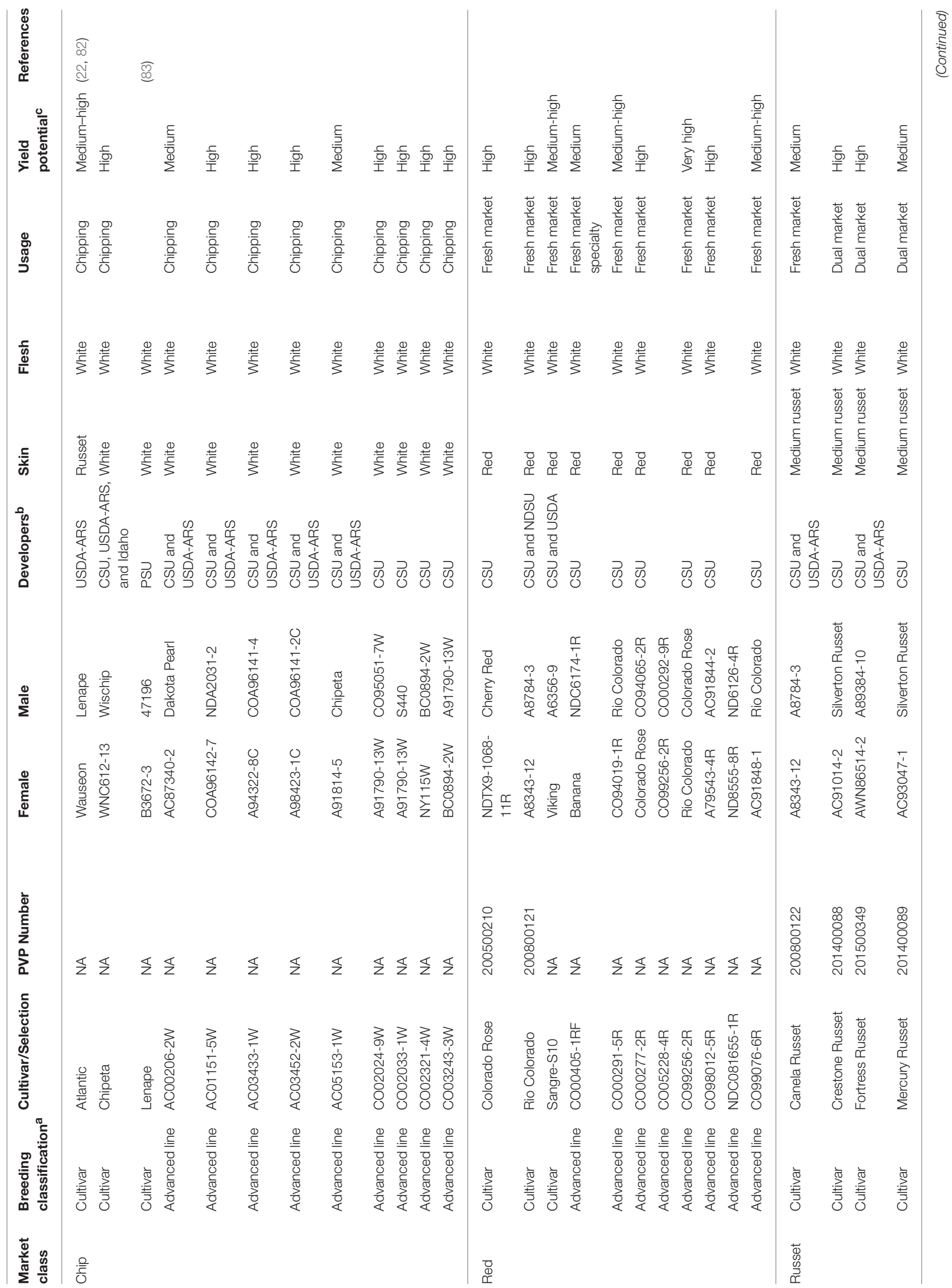




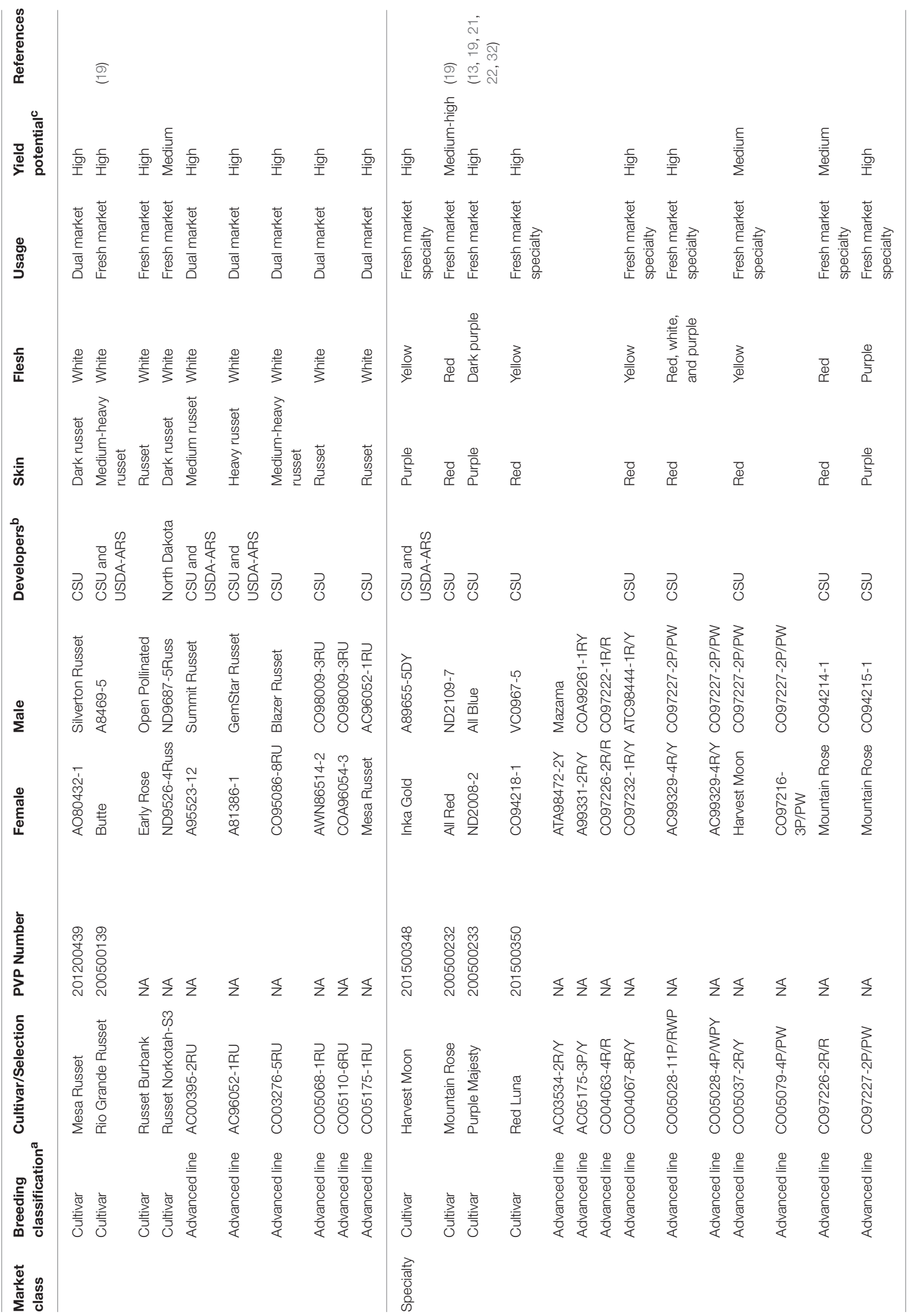




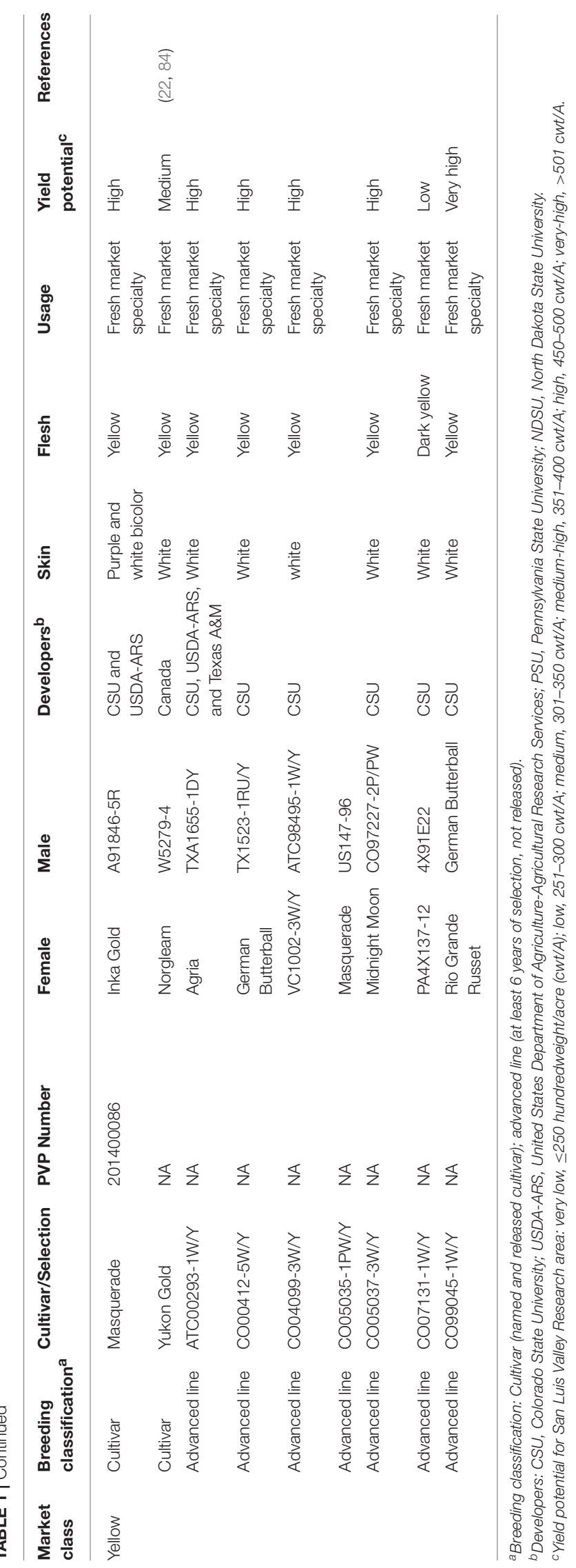


by the mean area of the chromatographic peaks among replicate injections $(n=2)$. UPLC- and GC-MS data were deconvoluted into spectral clusters using RAMClust (85). Metabolites were identified by matching mass spectra and retention indices and/or experimental or predicted retention times with in-house and external databases (86) including NIST (http://nist.gov), Golm Metabolome Database (87, 88), Lipid Maps (89), and Human Metabolome database (90). Confidence in metabolite annotations was based on guidelines of the Metabolomics Standards Initiative (91). UPLC may sometimes separate metabolite isomers, and these are observed as identical mass spectra at different retention times. Metabolite isomers are indicated as numbers next to metabolite names ("metabolite 01 ," "metabolite 02 ," etc.).

\section{Sample Preparation and Acid Digestion for Ionomics Analysis of Raw Potato Tubers}

A total of $150 \mathrm{mg}$ of raw freeze-dried potato tuber powder was added to a $16 \times 110 \mathrm{~mm}$ borosilicate glass test tube. Subsequently, $1.5 \mathrm{~mL}$ of $70 \%$ nitric acid (BDH Aristar ${ }^{\circledR}$ Plus) was added followed by $66.7 \mu \mathrm{L}$ of internal standard solution [10 ppm each of Bismuth (Bi), Gallium (Ga), Indium (In), Scandium (Sc), and Yttrium (Y)]. Samples were gently mixed, covered with plastic wrap, and digested overnight at room temperature. Next, samples were heated in a sand bath for $3 \mathrm{~h}$ at $120^{\circ} \mathrm{C}$, cooled at room temperature for $5 \mathrm{~min}$, and then $750 \mu \mathrm{L}$ of hydrogen peroxide (J.T. Baker, 30\% Ultrex ${ }^{\circledR}$ II Ultrapure reagent) was added to each sample. The solution was heated in a sand bath at $120^{\circ} \mathrm{C}$ for an additional hour. Samples were removed from the sand bath and allowed to cool to room temperature. The digest was transferred to $15 \mathrm{~mL}$ centrifuge tube and diluted to $10 \mathrm{~mL}$ using ultrapure $18.2 \mathrm{M} \Omega$ water, and $4.5 \mathrm{~mL}$ of the diluted solution was transferred to a new $15 \mathrm{~mL}$ centrifuge tube. The solution was subsequently diluted to a final volume of $15 \mathrm{~mL}$ using ultrapure water. The final solution contained internal standard concentrations of $20 \mathrm{ppb}$ in $3 \%$ nitric acid.

\section{Ionome Detection Using Inductively Coupled Plasma Mass Spectrometry (ICP-MS)}

Elemental concentrations of Arsenic (As), Aluminum (Al), Barium (Ba), Boron (B), Beryllium (Be), Cadmium (Cd), Calcium (Ca), Chromium (Cr), Cobalt (Co), Copper (Cu), Iron $(\mathrm{Fe})$, Lead $(\mathrm{Pb})$, Lithium (Li), Magnesium (Mg), Manganese (Mn), Molybdenum (Mo), Nickel (Ni), Phosphorous (P), Potassium (K), Selenium (Se), Sodium (Na), Strontium ( $\mathrm{Sr}$ ), Sulfur (S), Vanadium (V), Tungsten (W), and Zinc (Zn) were measured using an Elan DRC (Dynamic Reaction Cell) II mass spectrometer (PerkinElmer, Akron, OH, USA) connected to a Seaspray ${ }^{\mathrm{TM}}$ MEINHARD nebulizer and a quartz cyclonic spray chamber. Samples were introduced using an ASX-520 autosampler (CETAC Technologies, Omaha, NE, USA). Li, Be, $\mathrm{B}, \mathrm{Na}, \mathrm{P}, \mathrm{S}, \mathrm{Mg}, \mathrm{K}, \mathrm{Ca}, \mathrm{W}$, and $\mathrm{Pb}$ were measured in standard mode. To reduce polyatomic interferences, some elements were measured in DRC mode. Cd, Se, and As were measured in DRC mode using oxygen as the reactive gas. $\mathrm{Al}, \mathrm{V}, \mathrm{Cr}, \mathrm{Mn}, \mathrm{Fe}, \mathrm{Co}$, $\mathrm{Ni}, \mathrm{Cu}, \mathrm{Zn}, \mathrm{Sr}, \mathrm{Mo}$, and $\mathrm{Ba}$ were measured in DRC mode using ammonia as the reactive gas. Before analysis, the nebulizer gas flow and lens voltage were optimized for maximum Indium signal intensity $(56,008$ counts per second), with final values of $0.85(\mathrm{~L} / \mathrm{min})$ and 8.0 , respectively. A daily performance check was also run which ensured that the instrument was operating properly and obtained a $\mathrm{CeO}^{+}: \mathrm{Ce}^{+}$of 0.028 and a $\mathrm{Ba}^{++}: \mathrm{Ba}$ of 0.017 . A calibration curve was obtained by analyzing seven dilutions of a multi-element stock solution made from a mixture of single-element stock standards (Inorganic Ventures, Christiansburg, VA, USA). To correct for instrument drift a quality control (QC) solution (pooled sample, prepared by mixing $2 \mathrm{~mL}$ of each digested individual sample) was run every $10^{\text {th }}$ sample.

\section{Ionomics Data Processing}

Data was processed using Microsoft ${ }^{\circledR}$ Excel. Each element was subjected to internal standard corrections and subsequently drift corrected (92). Corrections were chosen based on minimizing the relative standard deviation (RSD) for the QC samples. After drift correction, samples were corrected for the dilution factor. Limits of detection (LOD) and limits of quantification (LOQ) were calculated as 3 times or 10 times the standard deviation of the blank divided by the slope of the calibration curve, respectively $(93,94)$. Final concentrations are reported as $\mathrm{ppb}(\mu \mathrm{g} / \mathrm{kg}$ of freeze-dried potato). Measured calculations below the LOQ were assigned to the LOQ/2 (95).

\section{Statistical Analysis}

For metabolites, Spearman's correlations and hierarchical clustering were conducted in $\mathrm{R}$ (81) using corr and hclust functions, respectively. Metabolites and elements were evaluated using analysis of variance (ANOVA) using the aov function in $\mathrm{R}$ (81). For ANOVA, a $p$ threshold of 0.05 was used following a Benjamini-Hochberg (96) adjustment using the p.adjust function in $\mathrm{R}$ (False Discovery Rate, FDR). Principal component analysis (PCA) of metabolites and elements was performed on mean-centered and unit variance scaled data using SIMCA v14.1 (Umetrics, Umea, Sweden). Z scores for metabolites were calculated using the relative abundance value of a metabolite compared to the mean and standard deviation of the metabolite's relative abundance across all samples (i.e., the population mean and standard deviation). $\mathrm{Z}$ scores were used to generate a heat map using the heatmap. 2 function of gplots package in $\mathrm{R}$ (97). Fold variation (FV) for cooked nutrient and bioactive compounds was calculated within and among market classes. Within market class mean FV ( $\mathrm{mFV}$ ) was calculated as ratio of the potato genotype with the highest metabolite mean peak area $(n=2)$ divided by the potato genotype with the lowest mean peak area $(n=2)$ within each potato market class for each nutrient and bioactive compound (Table 2). Among market classes $\mathrm{mFV}$ was calculated as the ratio of the highest average mean metabolite peak area of the potato market class divided by the lowest average mean peak area potato market class for each nutrient and bioactive compound (Table 2). Relative standard deviation (RSD) was determined for cooked and raw metabolites and between market classes within raw and cooked tubers. The RSD was calculated for each individual cultivar and 
TABLE 2 | Mean fold variation of bioactive and nutrient compounds identified in potato tubers.

\begin{tabular}{|c|c|c|c|c|c|c|c|c|c|c|}
\hline \multirow[t]{4}{*}{ Category } & \multirow[t]{4}{*}{ Class } & \multirow[t]{4}{*}{ Annotation } & \multicolumn{6}{|c|}{ Mean fold variation ${ }^{a}$} & \multirow[t]{4}{*}{ Health effects } & \multirow{4}{*}{$\begin{array}{l}\text { Selected } \\
\text { publications }\end{array}$} \\
\hline & & & \multicolumn{6}{|c|}{ Cooked } & & \\
\hline & & & \multirow[t]{2}{*}{ Market class ${ }^{b}$} & \multicolumn{5}{|c|}{ Cultivar ${ }^{c}$} & & \\
\hline & & & & Chip & Red & Russet & Yellow & Specialty & & \\
\hline & & Trigonelline & 2 & 4 & 10 & 3 & 68 & 5 & $\begin{array}{l}\text { Hypoglycemic } \\
\text { activity, } \\
\text { neuroprotective }\end{array}$ & (39) \\
\hline & \multirow[t]{2}{*}{ Amides } & Oleamide 01 & 2 & 5 & 5 & 3 & 4 & 8 & Vasorelaxant & (35) \\
\hline & & Oleamide 02 & 1 & 3 & 3 & 3 & 4 & 5 & & \\
\hline & \multirow[t]{3}{*}{ Flavonoids } & Apigenin & 1 & 4 & 3 & 3 & 3 & 4 & $\begin{array}{l}\text { Anticancer, } \\
\text { antiproliferative } \\
\text { activity }\end{array}$ & (29) \\
\hline & & $\begin{array}{l}\text { Kaempferol } \\
\text { 3-O-rutinoside }\end{array}$ & 48 & 14 & 15 & 13 & 9 & 636 & $\begin{array}{l}\text { Hypotensive } \\
\text { activity, } \\
\text { antihypertensive } \\
\text { activity }\end{array}$ & (33) \\
\hline & & Rutin & 4 & 38 & 39 & 64 & 37 & 21 & $\begin{array}{l}\text { Anticancer, } \\
\text { inhibition of tumor } \\
\text { growth }\end{array}$ & (99) \\
\hline & \multirow{15}{*}{ Glycoalkaloids } & Chaconine 02 & 1 & 2 & 2 & 4 & 2 & 3 & & \\
\hline & & Chaconine 03 & 1 & 5 & 4 & 9 & 3 & 5 & & \\
\hline & & Chaconine 04 & 2 & 4 & 3 & 11 & 4 & 4 & & \\
\hline & & Solanine 01 & 3 & 7 & 9 & 42 & 61 & 8 & Anticancer & $(100)$ \\
\hline & & Solanine 02 & 8 & 4 & 62 & 45 & 155 & 66 & & \\
\hline & & Solanine 03 & 1 & 2 & 2 & 4 & 3 & 3 & & \\
\hline & & Solanine 04 & 1 & 3 & 3 & 6 & 3 & 3 & & \\
\hline & & Solanine 05 & 2 & 4 & 7 & 45 & 7 & 7 & & \\
\hline & & Solanine 06 & 2 & 3 & 2 & 5 & 3 & 3 & & \\
\hline & & Solanine 07 & 2 & 7 & 3 & 26 & 3 & 8 & & \\
\hline & & Solanine 08 & 3 & 105 & 74 & 493 & 51 & 79 & & \\
\hline & & Solanine 09 & 2 & 8 & 7 & 8 & 19 & 5 & & \\
\hline & & Solanine 10 & 2 & 20 & 5 & 10 & 3 & 8 & & \\
\hline & & Solanine-like & 1 & 4 & 2 & 3 & 2 & 3 & & \\
\hline & & Tomatine & 2 & 11 & 12 & 12 & 18 & 46 & $\begin{array}{l}\text { Cholesterol } \\
\text { lowering }\end{array}$ & $(52)$ \\
\hline & \multirow[t]{3}{*}{ Phenolics } & Chlorogenic acid 01 & 3 & 3 & 2 & 3 & 2 & 9 & $\begin{array}{l}\text { Hypotensive } \\
\text { activity }\end{array}$ & $(37)$ \\
\hline & & Chlorogenic acid 02 & 7 & 6 & 3 & 9 & 5 & 30 & & \\
\hline & & Chlorogenic acid 03 & 40 & 16 & 9 & 43 & 24 & 526 & & \\
\hline
\end{tabular}


TABLE 2 | Continued

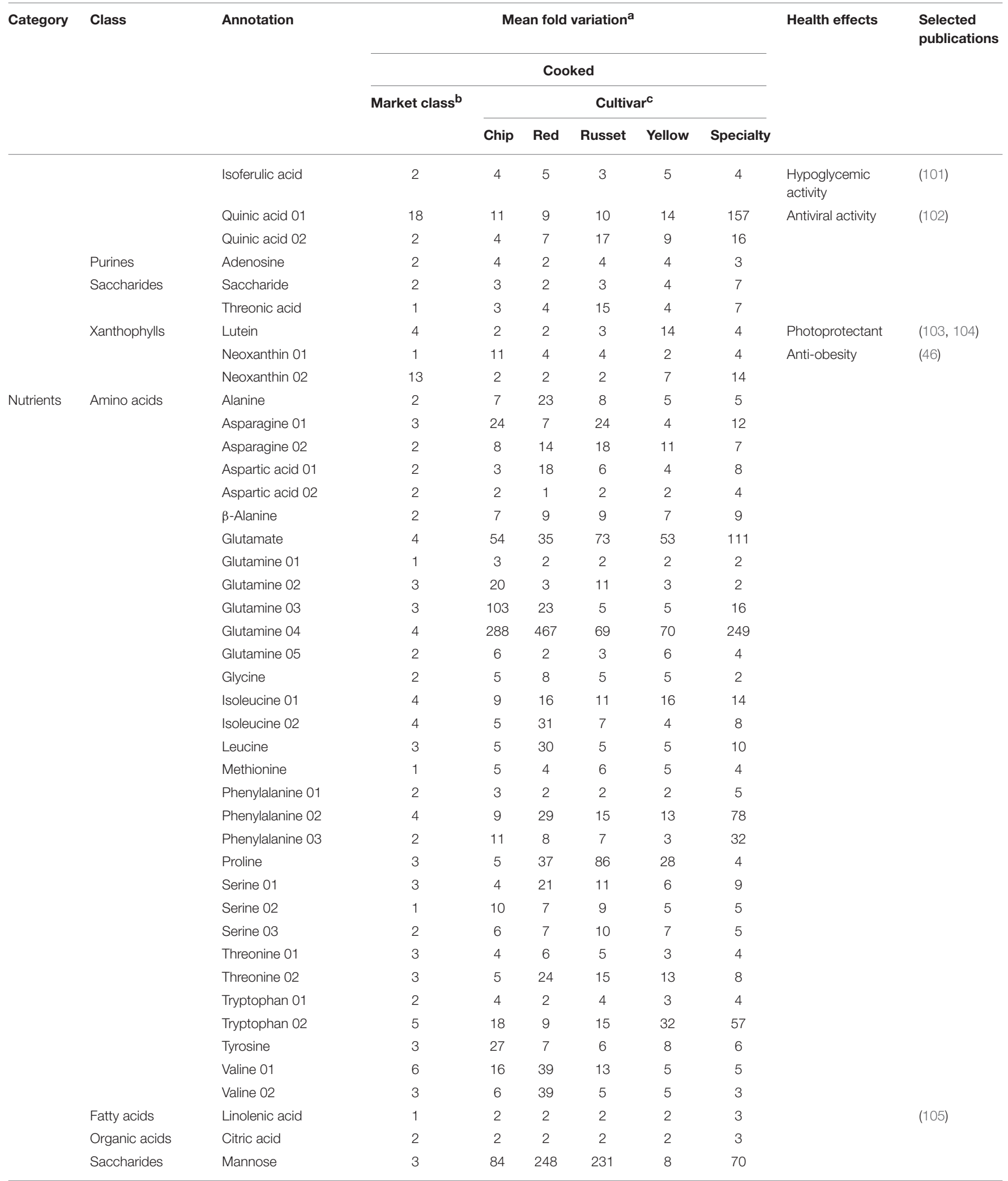


TABLE 2 | Continued

\begin{tabular}{|c|c|c|c|c|c|c|c|c|c|}
\hline \multirow[t]{4}{*}{ Category } & \multirow[t]{4}{*}{ Class } & \multirow[t]{4}{*}{ Annotation } & \multicolumn{5}{|c|}{ Mean fold variation ${ }^{a}$} & \multirow[t]{4}{*}{ Health effects } & \multirow{4}{*}{$\begin{array}{l}\text { Selected } \\
\text { publications }\end{array}$} \\
\hline & & & \multicolumn{5}{|c|}{ Cooked } & & \\
\hline & & & \multirow[t]{2}{*}{ Market class $^{b}$} & \multicolumn{4}{|c|}{ Cultivarc } & & \\
\hline & & & & Chip & Red & Russet & Yellow & & \\
\hline & \multirow[t]{8}{*}{ Vitamins } & $\alpha$-Tocopherol 01 & 1 & 2 & 2 & 2 & 2 & 2 & $(106)$ \\
\hline & & $\alpha$-Tocopherol 02 & 1 & 2 & 4 & 3 & 2 & 5 & \\
\hline & & $\gamma$-Tocopherol 01 & 2 & 3 & 2 & 4 & 3 & 2 & $(107)$ \\
\hline & & $\gamma$-Tocopherol 02 & 3 & 34 & 14 & 21 & 16 & 23 & \\
\hline & & Pantothenic acid 01 & 1 & 2 & 2 & 2 & 2 & 2 & $(108)$ \\
\hline & & Pantothenic acid 02 & 1 & 2 & 2 & 2 & 2 & 2 & \\
\hline & & Pyridoxal & 2 & 3 & 3 & 2 & 3 & 6 & $(109)$ \\
\hline & & Pyridoxine & 1 & 1 & 2 & 3 & 2 & 2 & $(110)$ \\
\hline
\end{tabular}

${ }^{a}$ Within market class mean Fold Variation = (potato genotype with the highest metabolite mean peak area)/(potato genotype with the lowest mean peak area). Among market class mean Fold Variation = (potato market class with highest metabolite mean peak area)/(potato market class with the lowest metabolite mean peak area).

${ }^{b}$ Among market class mean Fold Variation.

${ }^{c}$ Within market class mean Fold Variation.

then averaged (via mean) across treatments and represented as a heat map using the heatmap.2 function in gplots (97). Spearman's rank correlations of cooked vs. raw metabolites was visualized using the corrplot package in $\mathrm{R}$ (111).

\section{RESULTS}

\section{Metabolomics Detected and Quantified a Diverse Set of Bioactives and Nutrients in Potato Tuber}

Non-targeted UPLC- and GC-MS metabolomics was conducted on 60 potato genotypes that span 5 market classes: russet, red, chip, yellow, and specialty (Table 1). The population was developed to characterize tuber chemical diversity with diverse genetics, however all samples would be considered acceptable in the consumer market. The sample set included released cultivars and advanced breeding lines, as well as several levels of maturation, yield potential, and a diverse breeding pedigree as the basis for genotypic diversity.

The UPLC- and GC-MS analyses detected 1,757 and 899 compounds, respectively, for a total of 2,656 compounds. Of the 2,656, 185 were annotated as a known metabolite, 42 are known nutrients, and 43 were classified as a bioactive compound ("bioactives"; Table 2). The bioactives included several types of alkaloids, amides, amines, polyamines, phenolics (coumarins, flavonoids), and terpenes (carotenoids). The nutrients included amino acids, fatty acids, organic acids, saccharides, and vitamins (Table 2). An additional 76 compounds were classified as lipids and 24 were classified as "other." Further, the potato metabolome contained many essential nutrients such as amino acids (isoleucine, leucine, lysine, methionine, phenylalanine, threonine, tryptophan, and valine). We were also able to detect the essential fatty acid linolenic acid, and essential vitamins such as vitamin $\mathrm{E}$ ( $\alpha$ - and $\gamma$-tocopherol), vitamin B5 (pantothenic acid), vitamin B6 (pyridoxal and pyridoxine) (Table 2).

\section{Cooking Influences the Potato Tuber Metabolome Resulting in the Reduction of Many Bioactives and Nutrients}

The metabolite profiles of cooked and raw potato tuber were compared to understand (i) which nutrients and bioactives are sensitive to high temperatures and are reduced during cooking and (ii) if potato genotypes with the highest levels of nutrients and bioactives in raw tuber are also highest in cooked tuber. These data are important to understand the potential to screen potato tuber to identify unique genotypes with superior health properties.

Metabolite profiles of the 60 genotypes (cooked and raw) were evaluated using PCA (Figure 1, left; PC 1, 17.35\% of the variation). Overall, 1,977 out of the 2,656 detected compounds (74.4\%) varied due to cooking (ANOVA, FDR adjusted $p<$ $0.05)$. Cooking influenced the abundance of 24/43 bioactives (55.8\%) and 37/42 nutrients (88.1\%) (ANOVA, FDR adjusted $p<0.05$, Supplementary Table 1). The PCA loadings plot indicates no major trend in all bioactives, nutrients, lipids (e.g., some nutrients increased, and others decreased; Figure 1). The effects of cooking were further evaluated with a fold variation analysis ( $\log _{2}$ cut-off of \pm 0.5 ) and show that $41 \%$ $(1,102$ of 2,656$)$ of the metabolites did not vary with cooking, $33 \%$ (864 of 2,656) were more abundant in cooked potato, and $26 \%$ (690 of 2,656) were more abundant in raw potato (Figure 2A). Several bioactives decreased following cooking including neoxanthin, glykoalkaloids ( $\alpha$-solamarine, solanine, chaconine, and some of their isomers), calystegine A3 and calystegine B2 (Figure 2B). Nutrients that decreased following cooking include most amino acids and linolenic acid (Figure 2C). Importantly, several bioactives and nutrients did not vary with cooking such as chlorogenic acid, tomatine, rutin, oleamide, trigonelline, pantothenic acid, pyridoxal, and $\gamma$-tocopherol (Figures 2B,C). Further, multiple lipids were observed to vary with cooking, however there was no major trend of increasing 

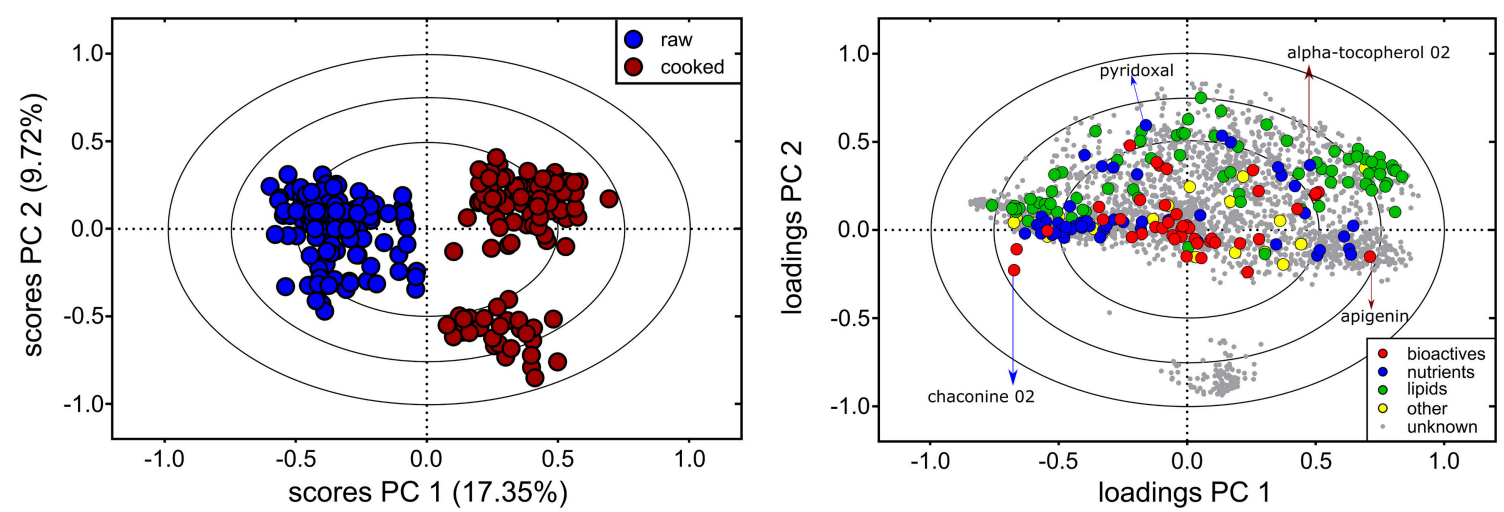

FIGURE 1 | Influence of cooking on the potato tuber metabolome. Principal Component Analysis (PCA) of the 60 cooked (red) and raw (blue) potato tuber metabolomes show that cooking was a major facet of metabolite variation, indicated by separation along PC 1 in the scores plot (left). Metabolite variation attributed to other factors was also observed (i.e., PC 2). The 2,656 metabolites detected are shown on the PC loadings plot (right), and colors represents metabolite class (bioactives, nutrients, lipids, others, and unknowns). Example nutrients and bioactives are indicated by arrows. Red arrows indicate nutrients or bioactives more abundant in cooked potato tubers and blue arrows indicate nutrients or bioactives more abundant in raw potato tubers. The PCA loadings and scores plot are correlation scaled and ellipses denote $0.5,0.75$, and 1.0 correlation values.
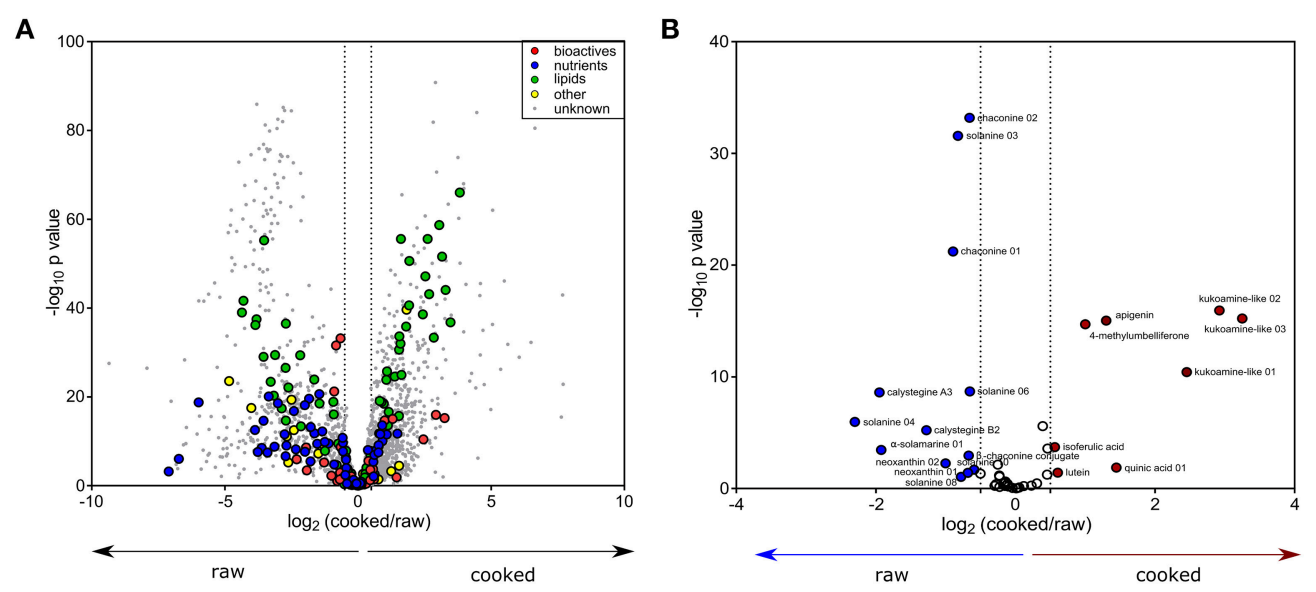

C

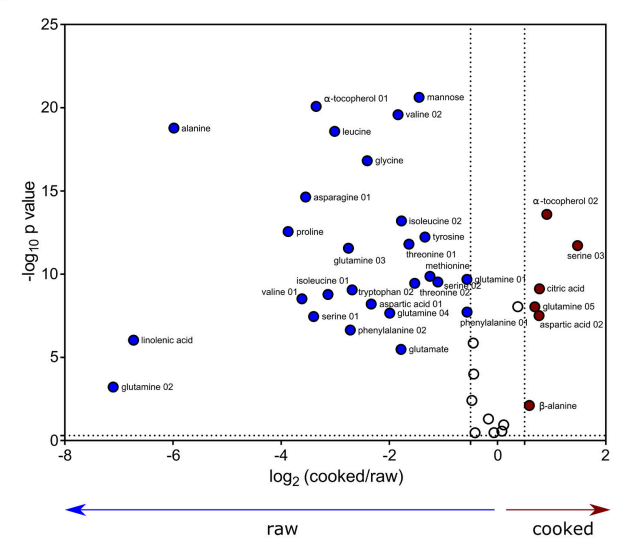

D

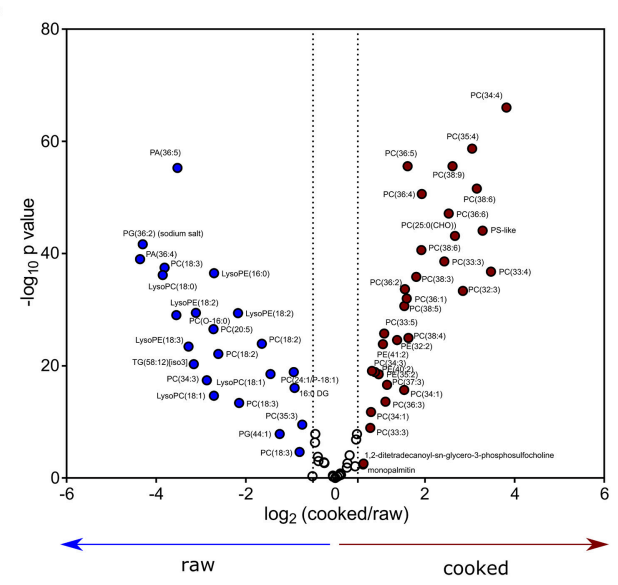

FIGURE 2 | Variation in cooked and raw potato tuber metabolites. (A) Volcano plot for the differential abundance ( $\log _{2}$ cooked/raw, x-axis) and significance (-log 10 FDR adjusted $p$-value, $y$-axis) of 2,656 metabolites (colored circles) detected by UPLC- and GC-MS across 60 cultivars of raw and cooked potato tubers. Color represents metabolite class, and vertical dashed lines are a threshold of cooked/raw $\left[\log _{2}\right.$ (cooked/raw) $<-0.5$ or $\left.>0.5\right]$. Subsets of the volanco plot in (A) were recreated for (B) bioactives, (C) nutrients, and (D) lipids. The subset volcano plots are colored to indicate metabolites reduced during cooking (blue), increased during cooking (red), or metabolites that did not vary due to cooking (white). 
or decreasing in abundance according to lipid chemical class (Figure 2D).

\section{Market Class Had a Minor Influence on the Abundance of Nutrients and Bioactives}

Analysis of the metabolites detected in both raw and cooked potato reveal market class differences (Figures 3A,B), however, there was more metabolite variation within market classes than among market class (Table 2, Supplementary Table 1). The PC scores plots within raw potato showed most separation was due to the yellow market class along PC $1(10.83 \%$ of the variation). These potatoes have high carotenoid content resulting in yellow/orange internal flesh (e.g., the cultivar Yukon Gold) (112-115), and, not surprisingly, carotenoids were major contributors to the separation of the yellow market class from others (e.g., lutein, Figure 3A, right). Furthermore, the fatty acid linolenic acid was also more abundant in yellow potatoes (Figure 3A, right). Interestingly, the raw yellow potatoes had overall reduced levels of lipids compared to all other market classes (Figure 3A, right). The metabolite variation among market classes, specifically differences between yellow potatoes and all others, did exist for cooked potato but to a lesser extent (Figure 3B). Variation among market classes was observed via PC 4 of the analysis (5.03\% of the variation; Figure $3 \mathbf{B}$ ). The major contributor to the market class separation was the chip class, which has little nutritional relevance as these potatoes are rarely consumed in the fresh market. Separation of yellow potatoes is observed along PC 5 (4.42\% of the variation, Figure 3B), with linolenic acid and xanthophylls (neoxanthin and lutein) primarily contributing to this separation (Figure 3B, right).

\section{Metabolite Co-variation Analysis Supports the Potential to Breed for Genotypes With High Levels of Bioactives and Nutrients in Cooked Tuber}

The co-variation of 85 metabolites was evaluated among market classes, genotypes, and cooking by integrating a $\mathrm{z}$ transformation of the metabolite abundances with hierarchical clustering visualized as a heat map (Figure 4). This result further supports that sets of nutrients/bioactives were (i) higher in raw tuber, (ii) higher in cooked tuber, or (iii) were not influenced by cooking. For example, a coumarin, 4-methylumbelliferone, isoferulic acid, and apigenin were more abundant in cooked tuber, whereas $\alpha$ solamarine and linolenic acid were more abundant in raw tuber. Chlorogenic acid, kaempferol-3-O-rutinoside, quinic acid, and oleamide were not influenced by cooking.

The heat map further demonstrates differences between potato market classes. The xanthophyll neoxanthin was more abundant in both raw and cooked yellow potatoes (Figure 4) and linoleic acid was more abundant in raw yellow potatoes as
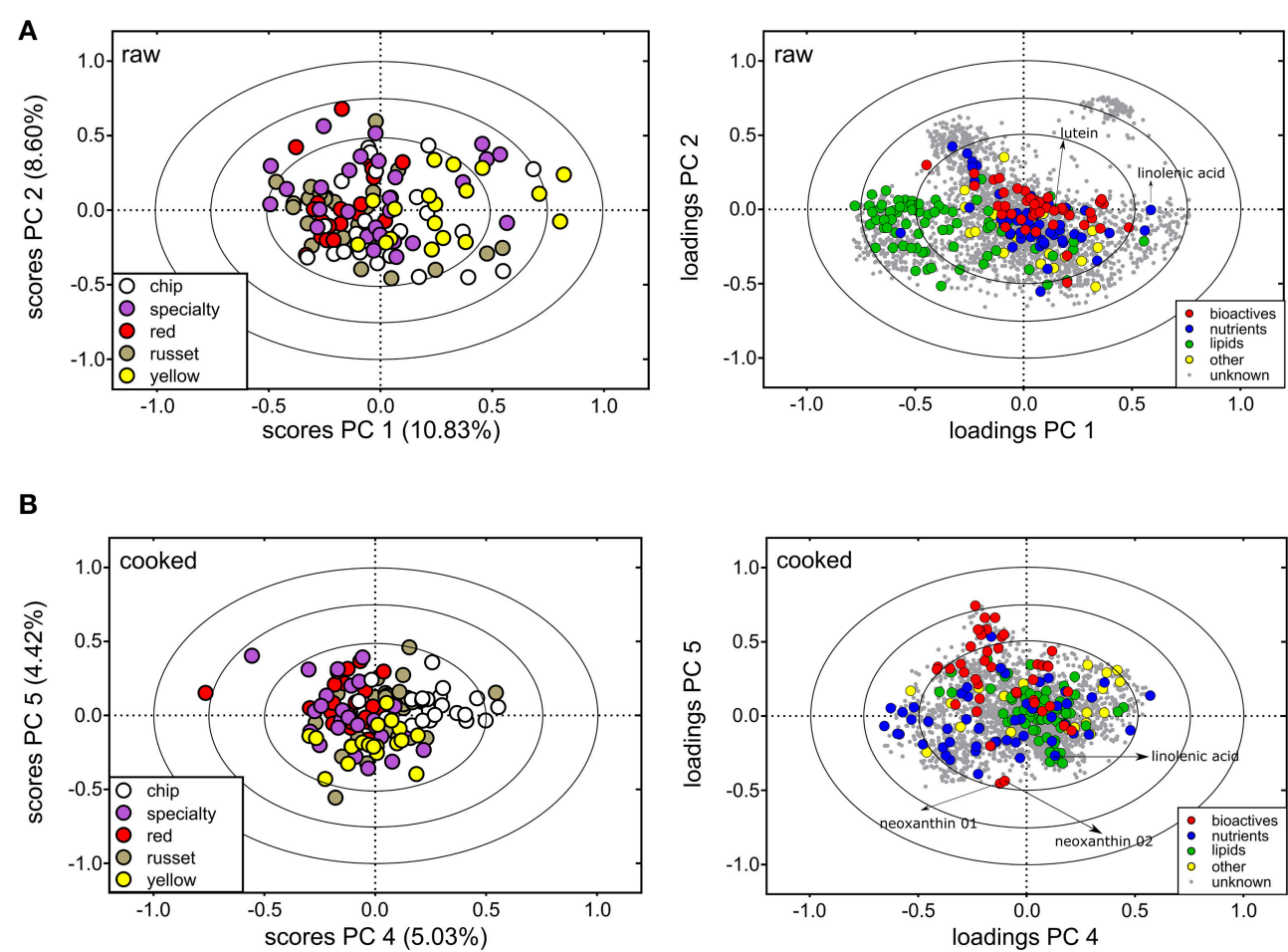

FIGURE 3 | Metabolite variation among potato market classes. PCA analysis for (A) raw tuber and (B) cooked tuber colored according to potato market class. For raw potato, PC 1 and PC 2 explained variation among market class for 124 metabolites (colored circles). For cooked potato, PC 4 and PC 5 separated market class explained by 100 metabolites. Metabolites denoted on the PCA loadings plot exhibit increased abundance in yellow potato. PCA loadings and scores plot are correlation scaled and ellipses denote $0.5,0.75$, and 1.0 correlation values. 


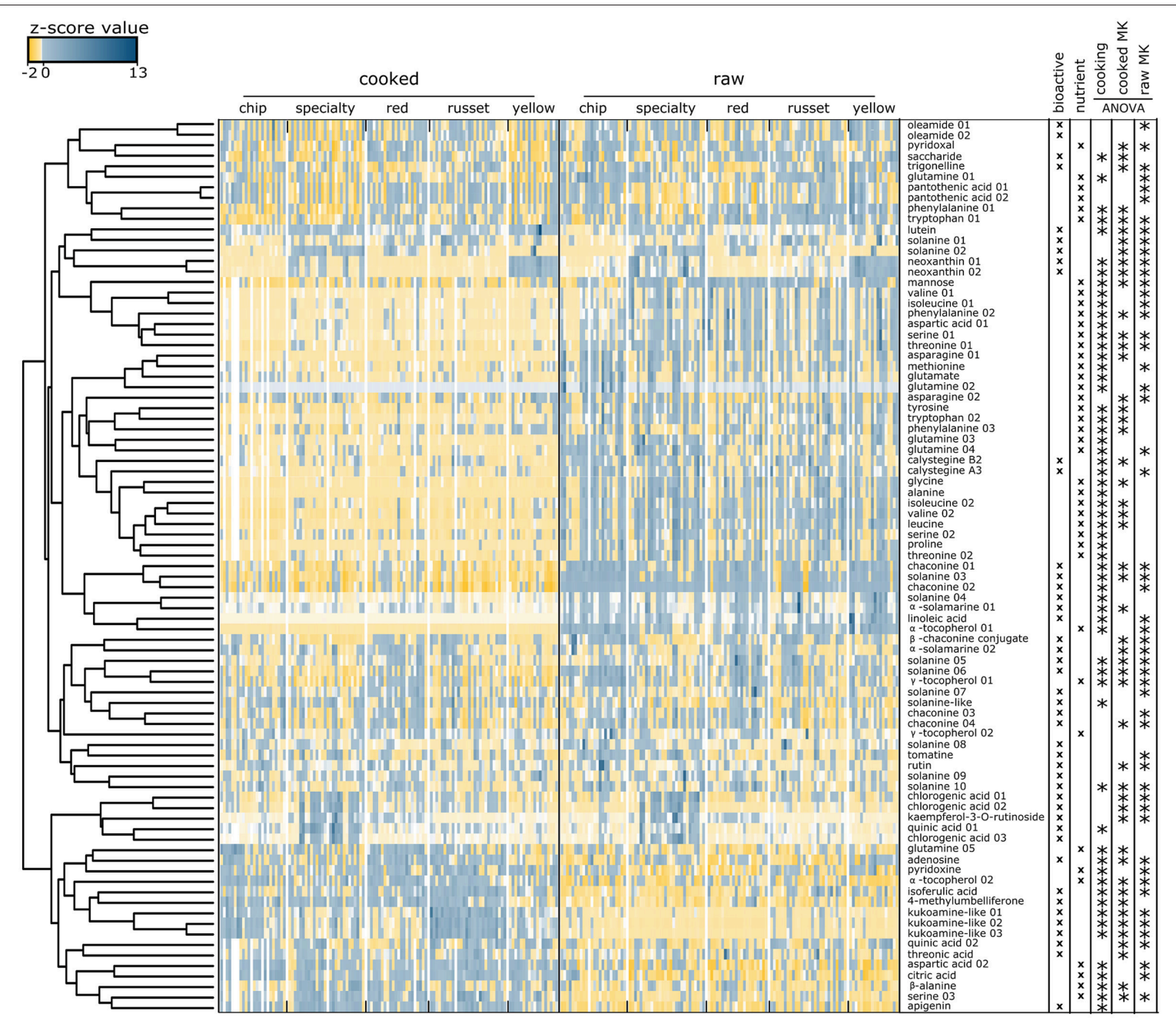

FIGURE 4 | Heat map of nutrients and bioactive compounds identified in cooked and raw potato tubers. Z-score values of the 85 metabolites annotated as nutrients or bioactives evaluated by hierarchical clustering. Two main clusters were formed: metabolites in high abundance in raw tubers and low abundance in cooked tubers (top), and metabolites in low abundance in raw and high abundance in cooked (bottom). Each colored square represents the centered and scaled relative abundance of a metabolite (Z-score). Z-scores were calculated as follows: $z=(X-\mu) / \sigma$, where $X$ is the relative abundance of a metabolite, $\mu$ is the mean abundance for the metabolite among all samples, $\sigma$ is the standard deviation among all samples. Hierarchical clustering was performed using Euclidian distances. Metabolite names with a number indicate isomers of the same compound. Statistical significance was calculated using a one-way ANOVA and adjusted for false discovery.

compared to other market classes. Specialty raw potatoes had more chlorogenic acid, kaempferol-3-O-rutinoside, and quinic acid when compared to russet, chip, yellow, and red potatoes. Vitamin B5 (pantothenic acid) was less abundant in specialty potato and the alkaloid trigonelline was less abundant in red potatoes. Cooked russets and chips had the most kukoamine compared to red, yellow, and specialty potatoes (Figure 4).

\section{Increased Metabolite Variation Was Observed Within Market Classes Than Among Market Class}

Fold Variation (FV) analysis of cooked nutrient and bioactive compounds revealed more variation within market class than among market class (Table 2). The extent of variation within market class was defined by a mean FV (mFV) of 30 bioactives or 19 nutrients. The data further support that most mean nutrient and metabolite abundances did not vary among market class. For the entire potato population, there was a $\mathrm{mFV}$ of 4 for all nutrients and bioactives. In general, bioactives exhibited greater variation in the full potato population ( $\mathrm{mFV}$ of 43 bioactives $=5$ ) compared to nutrients (mFV of 42 nutrients $=2$ ). However, market classes differed more broadly in terms of the range of variation for bioactives and nutrients. Specialty potatoes exhibited the greatest variation for all metabolites $(\mathrm{mFV}=42)$, and yellow potatoes had the lowest total variation $(\mathrm{mFV}=12)$. For bioactives, specialties had the most variation $(\mathrm{mFV}=64)$ and chips had the least variability $(\mathrm{mFV}=10)$. For nutrients, reds had the highest variation $(\mathrm{mFV}=29)$ and yellows had the least $(\mathrm{mFV}=9)$. 


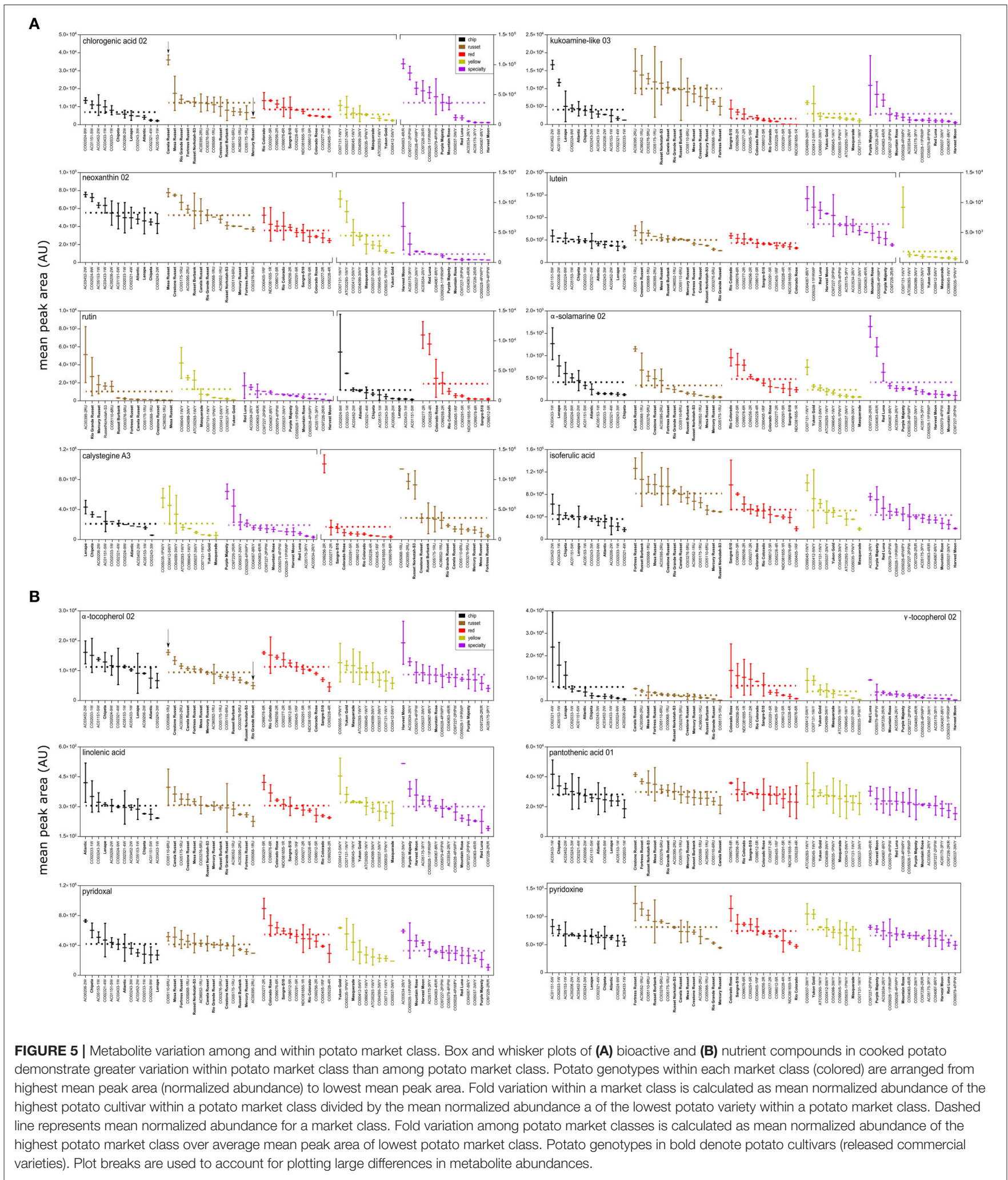

The variation of important bioactive and nutrient compounds was also visualized as box plots (Figure 5). Three key trends were observed in the data: (i) there were minimal differences in mean metabolite abundance among market classes; (ii) metabolites were normally distributed within market classes; and in some instances; (iii) select potato genotypes had significantly 
more of a compound than most. For example, chlorogenic acid displayed minor overall variation among market classes, exhibited a normal distribution within a market class, and one russet (Canela Russet) and several specialty genotypes (CO04063-4R/R and CO97227-2P/PW) had significantly more chlorogenic acid than most genotypes (Figure 5A). Similar trends were observed for other bioactives (Figure 5A). Some compounds were more abundant among market classes, such as lutein and neoxanthin, however these were also highly abundant in specialty potatoes that have been developed to also have yellow internal flesh (Harvest Moon, Red Luna, AC03534-2R/Y, AC05175-3P/Y, CO04067-8R/Y, and CO05037$2 \mathrm{R} / \mathrm{Y}$; Figure 5A). Interestingly, the alkaloid calystegeine A3, was overall more abundant in the russet market class, but a specific red potato, CO99256-2R has significantly greater quantities (Figure 5A) than all russet potatoes. Similar trends are observed for bioactive compounds such as rutin, $\alpha$-solamarine, and isoferulic acid (Figure 5).

Nutrient compounds also demonstrated similar patterns (Figure 5B). Overall, vitamins ( $\alpha$-tocopherol, $\gamma$-tocopherol, pantothenic acid, pyridoxal, and pyridoxine) did not vary among market classes and had a normalized distribution within market class. Linolenic acid also exhibited the same pattern where a single specialty potato (CO05037-3WY) had significantly more linolenic acid than most potato genotypes (Figure 5B). Overall, nutrient compounds were stable across genotypes except for linolenic acid.

\section{Bioactives and Nutrients Found in Raw Potato Tubers Correlate With Cooked Potato Tubers}

The data was evaluated to understand metabolite correlations between raw and cooked tuber to indicate the potential for analysis of raw tubers to predict cooked tuber phenotypes. Spearman rank correlation was performed on the 85 identified bioactive and nutrient compounds (Table 2 and Figure 6, $r_{s}$ $>|0.205| ; p<0.05)$. Most of the 85 metabolite correlations exhibited a positive relationship (Figure 6, right). Overall, 63 of the 85 compounds $(75 \%)$ significantly $(p<0.05)$ correlated. The metabolite classes that did not correlate between raw and cooked potato included most amino acids, $\alpha$-tocopherol 02, and 4-methylumbelliferone (Figure 6). The strongest correlations between raw and cooked potato were for glycoalkaloids, xanthophylls, and chlorogenic acid (Figure 6).

Next, the metabolite data was evaluated within cultivar to understand how metabolites can vary among tubers, within a genotype. Within-cultivar variation was evaluated using coefficient of variation (CV) calculated among $n=2$ randomly selected tubers per cultivar (Figure 6). The data reveals differences in tuber-to-tuber variation within cultivar for many metabolites. Overall, raw potato tubers had the highest tuber-to-tuber variation, with nutrients having more tuber-totuber variation compared to bioactive compounds (Figure 6). Within nutrients, free amino acids were among the classes of compounds with the most tuber-to-tuber variation (Figure 6,

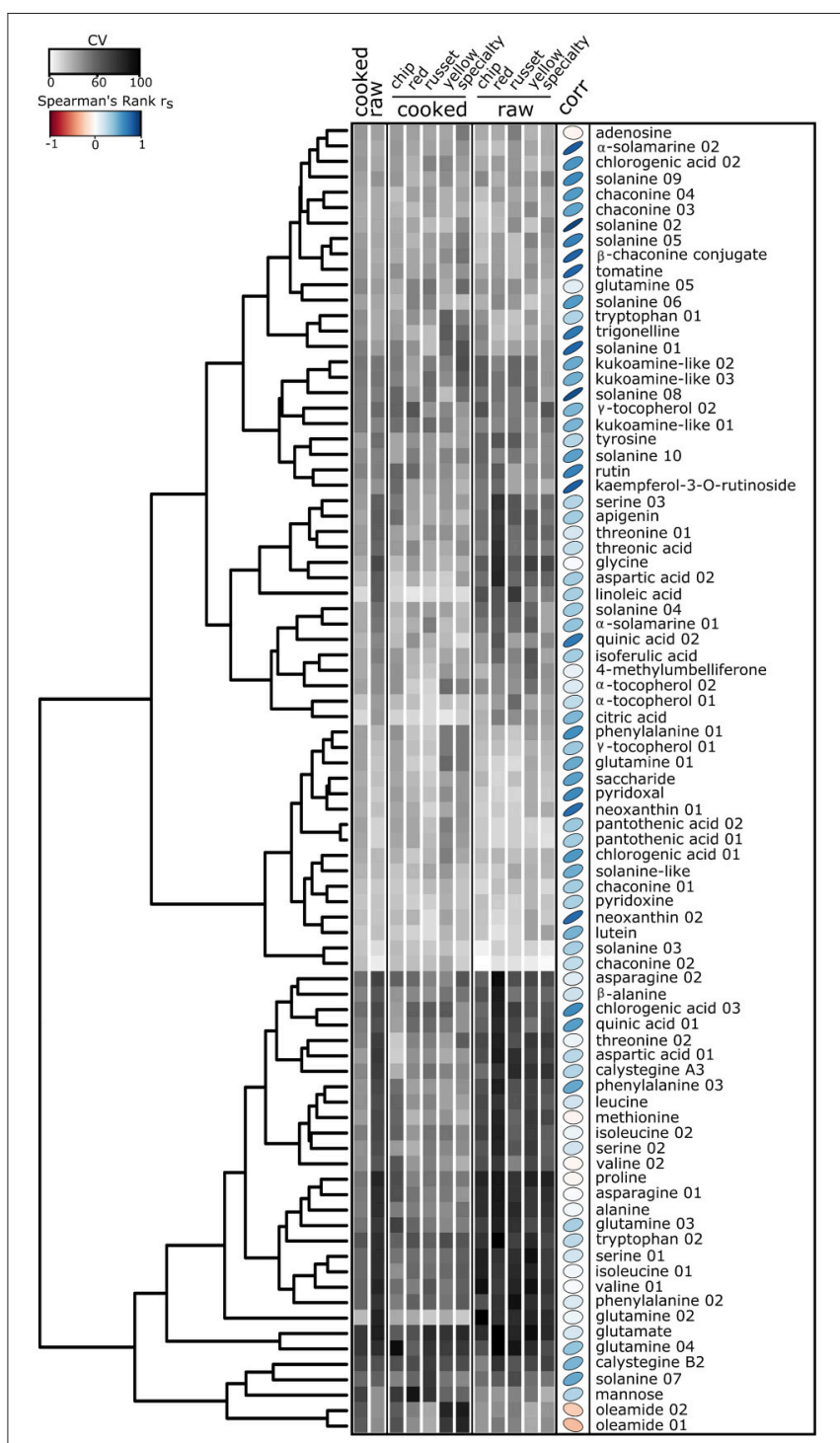

FIGURE 6 | Heat map of the relative standard deviation of nutrients and bioactive compounds identified in cooked and raw potato tubers. Gray squares represent the mean coefficient of variation (CV) for each of the 85 nutrients and bioactives within raw or cooked samples $(n=120)$, and among market class within raw or cooked tubers. CV was calculated as: $\mathrm{CV}=\sigma / \mu$ * 100 , where $\sigma$ is the standard deviation or the metabolite for each individual cultivar within a treatment and $\mu$ is the mean abundance for the metabolite for each individual cultivar within a treatment. The $\mathrm{CV}$ is calculated for each individual cultivar, averaged across treatments, and represented as a heat map. Hierarchical clustering was performed using Euclidian distances. Spearman's rank correlation $r_{s}$ (corr) between cooked and raw metabolites color and ellipse eccentricity denote $r_{s}$.

bottom). However, several vitamins and bioactives showed little tuber-to-tuber variation, such as chlorogenic acid 02 , neoxanthin 02 , and glycoalkaloids. Ultimately, metabolites with low CVs and strong correlation values will be ideal targets for future efforts to screen and breed for genotypes with health benefits. Metabolites that meet these criteria include glycoalkaloids, neoxanthin 01 , neoxanthin 02, pyridoxal, chlorogenic acid 01 (Figure 6). 

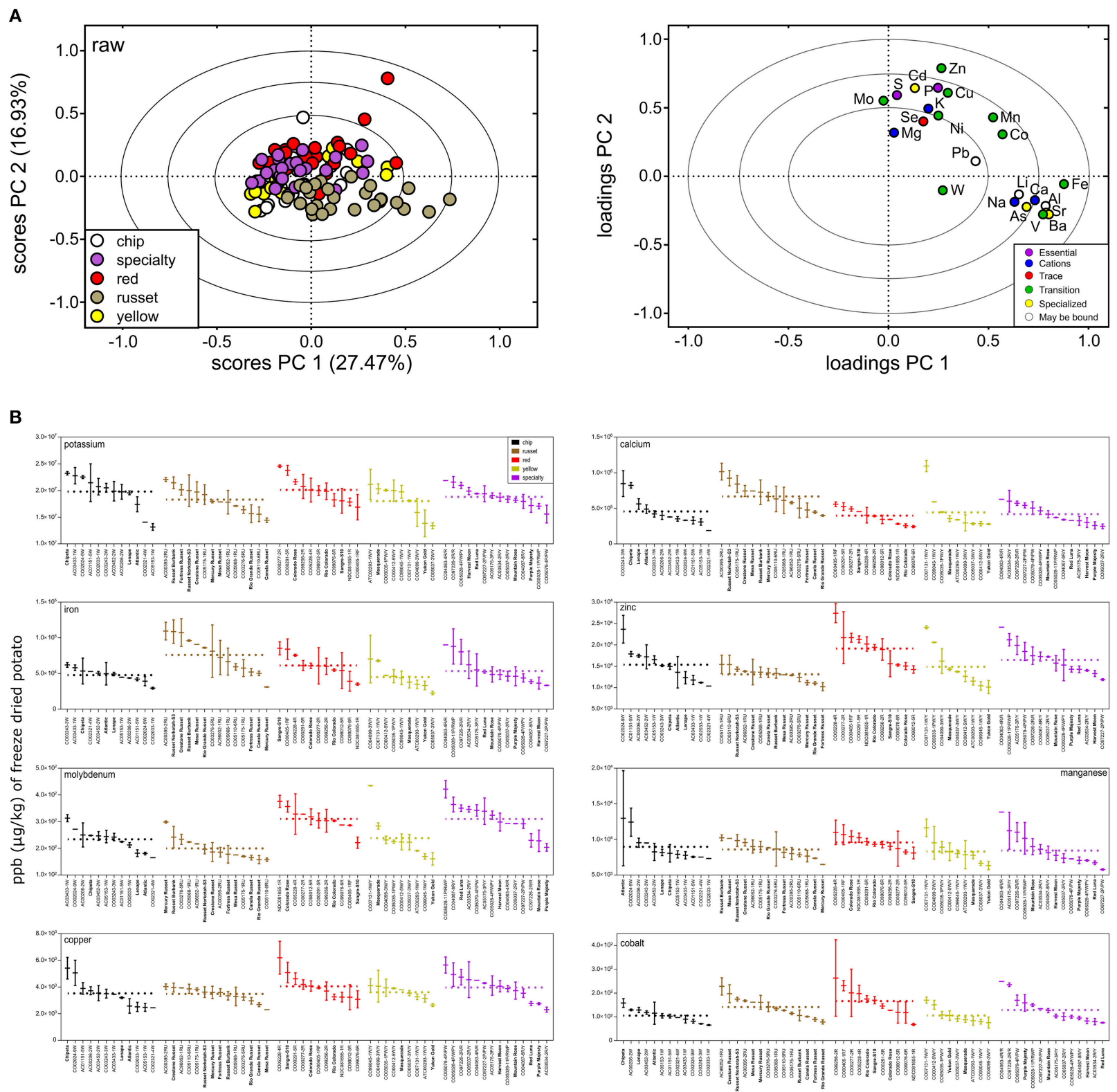

FIGURE 7 | Mineral variation in raw potato tuber. (A) PCA was performed on the potato ionome and colored according to potato market class (scores plot, left). PC 1 and PC 2 explained variation among market class for 23 elements (loadings plot, right). The PCA loadings and scores plot were correlation scaled and ellipses denote $0.5,0.75$, and 1.0 correlation values. (B) Box and whisker plots of micro- and macronutrient distribution highlight greater variation within potato market class than among potato market class. Potato genotypes within each market class (colored) are arranged from highest mean ppb $(\mu \mathrm{g} / \mathrm{kg})$ of freeze-dried potato to lowest. Mean fold variation within a market class is calculated as mean $\mathrm{ppb}(\mu \mathrm{g} / \mathrm{kg})$ of freeze-dried potato of highest potato cultivar within a potato market class divided by mean $\mathrm{ppb}(\mu \mathrm{g} / \mathrm{kg})$ of freeze-dried potato of lowest potato variety within a potato market class. Dashed line represents mean ppb $(\mu \mathrm{g} / \mathrm{kg})$ of freeze-dried potato for a market class. Mean fold variation between potato market classes is calculated as mean ppb $(\mu \mathrm{g} / \mathrm{kg})$ of freeze-dried potato of highest potato market class divided by mean $\mathrm{ppb}(\mu \mathrm{g} / \mathrm{kg})$ of freeze-dried potato of lowest potato market class. Potato genotypes in bold denote potato cultivars (released commercial varieties). Al, aluminum; As, arsenic; Ba, barium; Cd, cadmium; Ca, calcium; Co, cobalt; Cu, copper; Fe, iron; Pb, lead; Li, lithium; Mg, magnesium; Mn, manganese; Mo, molybdenum; Ni, nickel; P, phosphorous; K, potassium; Se, selenium; Na, sodium; Sr, strontium; S, sulfur; W, tungsten; V, vanadium; and Zn, zinc.

Potato Genetics Influenced Potato Mineral Content Within and Among Market Classes

Ionomics analysis was performed using ICP-MS to evaluate variation of minerals in raw potato. A panel of 26 elements were detected, however $\mathrm{B}, \mathrm{Be}$, and $\mathrm{Cr}$ were below limit of quantification. Similar trends were observed in minerals as with metabolites (Figure 7), specifically for variation among and within market classes. PCA showed separation among potato 
market classes (Figure 7A) with the largest separation in PC 1 and PC 2 (explained $44.4 \%$ of the dataset variability) (Figure 7A). The PCA showed russets to have a more unique mineral profile compare to all other markets classes. This was attributed to increased concentration of iron, calcium, and vanadium and decreased concentration of potassium, zinc, and molybdenum (Figure 7A, right).

For the total potato population, the mineral content varied between $1.7 \mathrm{mFV}(\mathrm{Mg})$ and $5.8 \mathrm{mFV}(\mathrm{Ca})$ (Table 3). Significant variation in potato mineral content was further supported by analysis of variance (ANOVA) that showed mineral variation among market classes (Table 3). Mean elemental concentration for each potato genotype can be found in Supplementary Table 2. Overall, 17 (74\%) of the elements significantly varied among market class (ANOVA, FDR-adjusted $p<0.05$; Table 3). Specifically, iron, zinc, copper, and calcium significantly varied among market class, while magnesium did not (Table 3, Figure 7B). However, as with metabolites, most of the variation was within market class. Overall, element concentration between market classes exhibited 1-2 mFV; whereas $\mathrm{mFV}$ within market class ranged from 1 to 7 (Table 3). For example, among market classes Ca exhibited $2 \mathrm{mFV}$ (391, 414, 442, 464, and $662 \mathrm{mg} / \mathrm{kg}$ in freeze-dried potato, red, specialty, yellow, chip, and russet, respectively). On the other hand, within market class, $\mathrm{Ca}$ exhibit a $4 \mathrm{mFV}$ within chip genotypes and yellow potatoes, a $3 \mathrm{mFV}$ in russet and specialty potatoes, and a $2 \mathrm{mFV}$ within red potatoes (Table 3, Figure 7B, and Supplementary Table 2). Similar trends are observed with potassium: $1 \mathrm{mFV}$ between potato market classes vs. $2 \mathrm{mFV}$ within chip, russet and yellow market classes (Table 3). Interestingly, russet potatoes exhibited a $\mathrm{mFV}$ of $4(31.2 \mathrm{mg} / \mathrm{kg}$ in freeze-dried potato, Mercury Russet, to $1,090 \mathrm{mg} / \mathrm{kg}$ in freeze-dried potato, AC00395-2RU) in iron content which may allow for increasing potato iron content (Table 3, Figure 7B, and Supplementary Table 2).

\section{DISCUSSION}

Here, non-targeted metabolomics and ionomics was applied to evaluate chemical diversity and quantity of bioactives and nutrients among a diverse set of potato cultivars and advanced lines (Table 1). A biphasic extraction protocol was utilized to optimize the extraction of a wide range of chemical compounds (hydrophilic, amphiphilic, and lipophilic) for detection using multiple mass spectrometry techniques (UPLC- and GC-MS) $(62,76,77)$. These strategies allowed for the detection of 2,656 compounds present in the potato tuber metabolome (Figure 1) over ten-fold the number of compounds as previously reported $(16,116,117)$.

The analyses revealed compositional variation in raw and cooked potato tuber (Figure 1), both within and among potato market classes (Figures 3, 5, 7). Significant correlations between raw and cooked potato tuber (Figure 6) support the ability to predict cooked potato metabolite content based on raw tuber profiling. In our study, 85 compounds (Table 2) and 23 minerals (Table 3) were identified as nutrients or bioactives that varied within and among potato market classes, supporting the potential for new breeding targets for health.

The bioactive compounds detected in this study have demonstrated effects on human health (Table 2). Many of the metabolites reduce the incidence of a diverse set of chronic diseases and have shown activity against cancer [4methylumbelliferon, apigenin, rutin, chaconine, solanine, (23, 27-31, 98, 99)], hypertension [oleamide (35), kukoamine (36), kaempferol 3-O-rutinoside (33), chlorogenic acid (37)], diabetes [trigonelline (39), isoferulic acid (101), calystegine A3 (38), calystegine B2 (38, 40-42)], and obesity [neoxanthin (46, 47)]. For example, the polyamine kukoamine has demonstrative hypotensive activity (Table 2) (36). Additionally, the literature indicates that alkaloids such as calystegine A3 and calystegine B2 can be used as therapy against cancer, diabetes, and to stimulate the immune system $(38,48,118)$.

While potato genetics is diverse, this sample set was designed to only include genotypes that would be acceptable for commercial fresh market potato consumption. Furthermore, breeding programs and new potato genotypes are monitored for potato glycoalkaloid content due to their toxic effect on humans at high concentrations (48, 83, 119-122). For example, Lenape was removed from the market due to its toxic effects resulting from high glycoalkaloid content (83), but remained in breeding programs due to its agronomic qualities (progeny with high glycoalkaloid content are discarded) (82).

Potatoes contain a large quantity and diversity of glycoalkaloid compounds (Table 2, Figure 5A). These compounds have demonstrated activity in pest and pathogen resistance, are toxic to humans and animals, and impart a bitter taste $(48,83,120$, $122,123)$. Regulations, restrictions, and guidelines imposed on potato glycoalkaloid content have resulted in wild potato species with higher glycoalkaloid content when compared to cultivated potato, which highlights the heritability of plant metabolites (119-121). The low tuber-to-tuber variation in our population within a genotype lends credence to this notion (Figure 6) and provides evidence that metabolite content and concentration is under genetic control. While potato glycoalkaloids have demonstrated toxicity, recent studies reveal health-promoting effects and thus desirability. For example, potato glycoalkaloids have chemopreventive effects showing activity against skin, colon, stomach, and liver cancer (27-31, 123).

Low within-cultivar variation further supports the opportunity to breed for enhanced health properties of potato. Metabolites with low $\mathrm{CV}$ are ideal targets to screen and breed for health (Figure 6). For example, vitamins such as pantothenic acid, pyridoxal, pyridoxine, and $\alpha$-tocopherol exhibited low $\mathrm{CV}$ (Figure 6). In fact, recent research has determined the ability to breed for potato cultivars with improved vitamin content (124). The antioxidant, chlorogenic acid, is also an ideal target due to little within tuber variability and no impact on abundance or variation occurs with cooking (Figures 2B, 5A, 6, Table 2, and Supplementary Table 1). Furthermore, a recent study demonstrated that the biosynthesis of chlorogenic acid in potato is controlled at the transcriptional level $(57,125)$. 


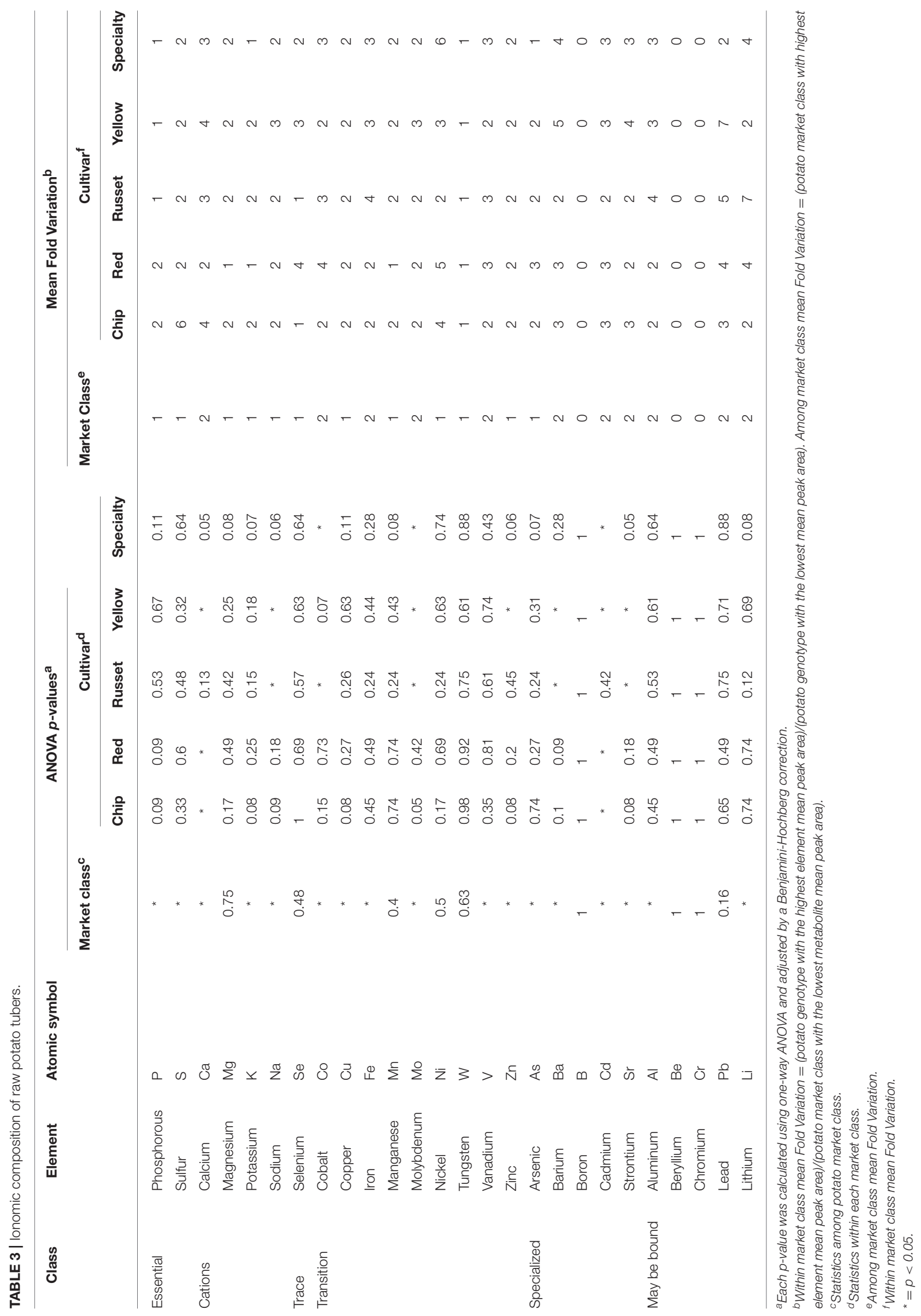


Yellow potatoes demonstrated very different metabolomes as compared to the other potato market classes (reds, russets, chips, and specialties; Figure 3) with the carotenoid content (lutein and neoxanthin) contributing significantly to this distinction (Figure 3). Potato carotenoid content varied among market class (14 mFV), which supports data from previous studies (59). Yellow potatoes also had reduced lipid content but increased levels of linolenic acid (Figures 3, 5B). This may indicate a metabolic relationship between primary and secondary lipid metabolism during tuber development (e.g., fatty acids and higher-level terpenes).

Potato tuber mineral content also varied (Table 3, Figure 7) within genotype and market class. Importantly, key minerals essential for human development and nutrition (e.g., Fe, Zn, Co, and $\mathrm{Ca}$ ) significantly varied within potato market class (Table 3 and Figure 7B). For example, iron showed a $3 \mathrm{mFV}$ within potato market classes, which supports data from previous studies (126). The combination of low phytic acid and high ascorbic acid in potato tubers increases iron bioavailability allowing for even small increases in potato tuber iron content to help overcome human iron deficiency (126). Studies focusing on increasing iron content in potato tubers revealed moderate heritability estimates (127). Interestingly, there were strong genetic correlations between multiple micronutrient concentrations (e.g., Fe and $\mathrm{Zn}$ ) indicating that efforts to breed for Fe can also result in increased levels of the essential mineral $\mathrm{Zn}$ (127).

The data presented here demonstrates the breadth of nutrients and bioactive compounds in potato tuber. Cooking had a major influence on phytochemical composition, however many vitamins and bioactive compounds were unaffected or had strong correlations between raw and cooked tuber. These specific vitamins and bioactive compounds are ideal targets for improving the health properties of potato tubers. Taken together,

\section{REFERENCES}

1. Daniels ME, Donilon TE, Bollyky TJ. The Emerging Global Health Crisis: Noncommunicable Diseases in Low- and Middle-Income Countries. New York, NY: Council on Foreign Relations Press (2014).

2. Roberts CK, Barnard RJ. Effects of exercise and diet on chronic disease. J Appl Physiol. (2005) 98:3-30. doi: 10.1152/japplphysiol.008 52.2004

3. Story M, Kaphingst KM, Robinson-O’Brien R, Glanz K. Creating healthy food and eating environments: policy and environmental approaches. Annu Rev Public Health (2008) 29:253-72. doi: 10.1146/annurev.publhealth.29.020907.090926

4. Nishida C, Uauy R, Kumanyika S, Shetty P. The joint WHO/FAO expert consultation on diet, nutrition and the prevention of chronic diseases: process, product and policy implications. Publ Health Nutr. (2004) 7:245. doi: 10.1079/PHN2003592

5. Kris-Etherton PM, Hecker KD, Bonanome A, Coval SM, Binkoski AE, Hilpert KF, et al. Bioactive compounds in foods: their role in the prevention of cardiovascular disease and cancer. Am J Med. (2002) 113(9 Suppl. 2):7188. doi: 10.1016/S0002-9343(01)00995-0

6. Cespedes EM, Hu FB. Dietary patterns: from nutritional epidemiologic analysis to national guidelines. Am J Clin Nutr. (2015) 101:899-900. doi: 10.3945/ajcn.115.110213

7. WHO. WHO/FAO Expert Consultation on Diet, Nutrition and the Prevention of Chronic Diseases. WHO Technical Report Series No. 916. (2003). the results of this study support the potential to breed for a healthier potato which could have significant implications in the fight against disease and malnutrition worldwide. Future work is warranted to determine the genetic and environmental factors that mediate chemical diversity in potato.

\section{AUTHOR CONTRIBUTIONS}

JC, DH, CB, JP, and AH wrote the manuscript and had primary responsibility for the final content. $\mathrm{DH}$, JP, and $\mathrm{AH}$ conceived the study. JC, CB, and $\mathrm{AH}$ collected and analyzed the metabolomics and ionomics data. All authors have read an approved the final manuscript.

\section{FUNDING}

The work of JC, DH, and $\mathrm{AH}$ was supported by the Colorado Certified Potato Growers Association, the Colorado Agricultural Experiment Station \#COL00761, and the USDANIFA Agriculture Special Research Grants Program - Potato Breeding Research \#2015-34141-23965.

\section{SUPPLEMENTARY MATERIAL}

The Supplementary Material for this article can be found online at: https://www.frontiersin.org/articles/10.3389/fnut.2018. 00036/full\#supplementary-material

Supplementary Figure 1 | UPLC-MS chromatogram of the biphasic extraction method. (A) Aqueous fraction, (B) organic fraction, and (C) combined (aqueous and organic) fraction. Arrows denote example differences among chromatograms.

Supplementary Table 1 | ANOVA analysis of bioactive and nutrient compounds identified in cooked and raw potato.

Supplementary Table 2 | Mean elemental concentration of potato tubers.
8. Kitts DD. Bioactive substances in food: identification and potential uses. Canad J Physiol Pharmacol. (1994) 72:423-34. doi: 10.1139/y94-062

9. Biesalski H-K, Dragsted LO, Elmadfa I, Grossklaus R, Müller M, Schrenk D, et al. Bioactive compounds: definition and assessment of activity. Nutrition (2009) 25:1202-5. doi: 10.1016/j.nut.2009.04.023

10. Bernhoft A, editor. A brief review on bioactive compounds in plants. In: Proceedings from a Symposium Held at The Norwegian Academy of Science and Letters. Oslo: Novus forlag (2010).

11. Birch PR, Bryan G, Fenton B, Gilroy EM, Hein I, Jones JT, et al. Crops that feed the world 8: potato: are the trends of increased global production sustainable? Food Security (2012) 4:477-508. doi: 10.1007/s12571-012-0220-1

12. Navarre DA, Shakya R, Hellmann H. Chapter 6: Vitamins, phytonutrients, and minerals in potato. In: Singh J, Kaur L, editors, Advances in Potato Chemistry and Technology. 2nd ed. San Diego, CA: Academic Press (2016). p. 117-66. doi: 10.1016/B978-0-12-800002-1. 00006-6

13. Lemos MA, Aliyu MM, Hungerford G. Influence of cooking on the levels of bioactive compounds in Purple Majesty potato observed via chemical and spectroscopic means. Food Chem. (2015) 173:462-7. doi: 10.1016/j.foodchem.2014.10.064

14. Navarre DA, Goyer A, Shakya R. Chapter 14: Nutritional value of potatoes: vitamin, phytonutrient, and mineral content. In: Singh J, Kaur L, editors, Advances in Potato Chemistry and Technology. San Diego, CA: Academic Press (2009). p. 395-424. doi: 10.1016/B978-0-12-374349-7.00014-3 
15. Parr AJ, Mellon FA, Colquhoun IJ, Davies HV. Dihydrocaffeoyl polyamines (kukoamine and allies) in potato (Solanum tuberosum) tubers detected during metabolite profiling. J Agric Food Chem. (2005) 53:5461-6. doi: 10.1021/jf050298i

16. Shepherd T, Dobson G, Verrall S, Conner S, Griffiths DW, McNicol J, et al. Potato metabolomics by GC-MS: what are the limiting factors? Metabolomics (2007) 3:475-88. doi: 10.1007/s11306-007-0058-2

17. Stushnoff C, Holm D, Thompson MD, Jiang W, Thompson HJ, Joyce NI, et al. Antioxidant properties of cultivars and selections from the Colorado Potato Breeding Program. Am J Pot Res. (2008) 85:267-76. doi: 10.1007/s12230-008-9032-4

18. Thompson MD, Thompson HJ. Chapter 1: Biomedical agriculture: a systematic approach to food crop improvement for chronic disease prevention. In: Sparks DL, editor Advances in Agronomy. Vol. 102. San Diego, CA: Academic Press (2009). p. 1-54.

19. Thompson MD, Thompson HJ, McGinley JN, Neil ES, Rush DK, Holm DG, et al. Functional food characteristics of potato cultivars (Solanum tuberosum L.): phytochemical composition and inhibition of 1-methyl-1nitrosourea induced breast cancer in rats. J Food Compos Anal. (2009) 22:571-6. doi: 10.1016/j.jfca.2008.09.002

20. Tian J, Chen J, Ye X, Chen S. Health benefits of the potato affected by domestic cooking: a review. Food Chem. (2016) 202:165-75. doi: 10.1016/j.foodchem.2016.01.120

21. Vinson JA, Demkosky CA, Navarre DA, Smyda MA. High-antioxidant potatoes: acute in vivo antioxidant source and hypotensive agent in humans after supplementation to hypertensive subjects. J Agric Food Chem. (2012) 60:6749-54. doi: 10.1021/jf2045262

22. Madiwale GP, Reddivari L, Stone M, Holm DG, Vanamala J. Combined effects of storage and processing on the bioactive compounds and proapoptotic properties of color-fleshed potatoes in human colon cancer cells. J Agric Food Chem. (2012) 60:11088-96. doi: 10.1021/jf303528p

23. Reddivari L, Vanamala J, Safe SH, Miller JC Jr. The bioactive compounds $\alpha$-chaconine and gallic acid in potato extracts decrease survival and induce apoptosis in LNCaP and PC3 prostate cancer cells. Nutr Cancer (2010) 62:601-10. doi: 10.1080/01635580903532358

24. USDA, ARS, Laboratory ND. USDA National Nutrient Database for Standard Reference, Release 28 (2016). Available online at: /nea/bhnrc/ndl (updated May 2016; cited 2017).

25. Drewnowski A, Fulgoni VL. Nutrient density: principles and evaluation tools. Am J Clin Nutr. (2014) 99:1223S-8S. doi: 10.3945/ajcn.113.073395

26. Gibson S, Kurilich A. The nutritional value of potatoes and potato products in the UK diet. Nutr Bull. (2013) 38:389-99. doi: 10.1111/nbu.12057

27. Piccioni F, Malvicini M, Garcia MG, Rodriguez A, Atorrasagasti C, Kippes N, et al. Antitumor effects of hyaluronic acid inhibitor 4-methylumbelliferone in an orthotopic hepatocellular carcinoma model in mice. Glycobiology (2012) 22:400-10. doi: 10.1093/glycob/cwr158

28. Kakizaki I, Kojima K, Takagaki K, Endo M, Kannagi R, Ito M, et al. A novel mechanism for the inhibition of hyaluronan biosynthesis by 4-methylumbelliferone. J Biol Chem. (2004) 279:33281-9. doi: 10.1074/jbc.M405918200

29. Gupta S, Afaq F, Mukhtar H. Selective growth-inhibitory, cell-cycle deregulatory and apoptotic response of apigenin in normal versus human prostate carcinoma cells. Biochem Biophys Res Commun. (2001) 287:914-20. doi: 10.1006/bbrc. 2001.5672

30. Lu M-K, Chen P-H, Shih Y-W, Chang Y-T, Huang E-T, Liu C$\mathrm{R}$, et al. $\alpha$-Chaconine inhibits angiogenesis in vitro by reducing matrix metalloproteinase-2. Biol Pharmaceut Bull. (2010) 33:622-30. doi: $10.1248 /$ bpb.33.622

31. Friedman M. Anticarcinogenic, cardioprotective, and other health benefits of tomato compounds lycopene, $\alpha$-tomatine, and tomatidine in pure form and in fresh and processed tomatoes. J Agric Food Chem. (2013) 61:9534-50. doi: 10.1021/jf402654e

32. Charepalli V, Reddivari L, Radhakrishnan S, Vadde R, Agarwal R, Vanamala JKP. Anthocyanin-containing purple-fleshed potatoes suppress colon tumorigenesis via elimination of colon cancer stem cells. J Nutr Biochem. (2015) 26:1641-9. doi: 10.1016/j.jnutbio.2015.08.005
33. Ahmad M, Gilani AUH, Aftab K, Ahmad VU. Effects of kaempferol3-O-rutinoside on rat blood pressure. Phytother Res. (1993) 7:314-6. doi: 10.1002/ptr.2650070411

34. Huang M-T, Smart RC, Wong C-Q, Conney AH. Inhibitory effect of curcumin, chlorogenic acid, caffeic acid, and ferulic acid on tumor promotion in mouse skin by 12-O-tetradecanoylphorbol-13-acetate. Cancer Res. (1988) 48:5941-6.

35. Hopps JJ, Dunn WR, Randall MD. Enhanced vasorelaxant effects of the endocannabinoid-like mediator, oleamide, in hypertension. Eur J Pharmacol. (2012) 684:102-7. doi: 10.1016/j.ejphar.2012.03.027

36. Funayama S, Yoshida K, Konno C, Hikino H. Structure of kukoamine A, a hypotensive principle of Lycium chinense root barks1. Tetrahedron Lett. (1980) 21:1355-6. doi: 10.1016/S0040-4039(00)74574-6

37. Watanabe T, Arai Y, Mitsui Y, Kusaura T, Okawa W, Kajihara Y, et al. The blood pressure-lowering effect and safety of chlorogenic acid from green coffee bean extract in essential hypertension. Clin Exp Hypertens. (2006) 28:439-49. doi: 10.1080/10641960600798655

38. Jockovic Na, Fischer W, Brandsch M, Brandt W, Dräger B. Inhibition of human intestinal $\alpha$-glucosidases by calystegines. J Agric Food Chem. (2013) 61:5550-7. doi: 10.1021/jf4010737

39. Zhou J, Chan L, Zhou S. Trigonelline: a plant alkaloid with therapeutic potential for diabetes and central nervous system disease. Curr Med Chem. (2012) 19:3523-31. doi: 10.2174/092986712801323171

40. Monago CC, Nwodo O. Antidiabetic effect of crude trigonelline of Abrus precatorius Linn seed in alloxan diabetic rabbits. J Pharm Res. (2010) 3:19169. doi: 10.4314/gjpas.v9i1.15975

41. Habtemariam S. A-glucosidase inhibitory activity of kaempferol-3-Orutinoside. Nat Prod Commun. (2011) 6:201-3.

42. Legrand D, Scheen AJ. Does coffee protect against type 2 diabetes? Rev. Med. Liege. (2007) 62:554-9.

43. Khan MM, Raza SS, Javed H, Ahmad A, Khan A, Islam F, et al Rutin protects dopaminergic neurons from oxidative stress in an animal model of Parkinson's disease. Neurotoxicity Res. (2012) 22:1-15. doi: 10.1007/s12640-011-9295-2

44. Koda T, Kuroda Y, Imai H. Protective effect of rutin against spatial memory impairment induced by trimethyltin in rats. Nutr Res. (2008) 28:629-34. doi: 10.1016/j.nutres.2008.06.004

45. Hur JY, Yunjo S, Bum-Hoi K, Kyungho S, Sohn NW, Kim HC, et al. Neuroprotective and neurotrophic effects of quinic acids from Aster scaber in PC12 cells. Biol Pharmaceut Bull. (2001) 24:921-4. doi: 10.1248/bpb.24.921

46. Miyashita K, Maeda H, Tsukui T, Okada T, Hosokawa M, editors. Antiobesity effect of allene carotenoids, fucoxanthin and neoxanthin from seaweeds and vegetables. In: II International Symposium on Human Health Effects of Fruits and Vegetables: FAVHEALTH 2007, Houston, TX. (2007) p. 841 .

47. Okada T, Nakai M, Maeda H, Hosokawa M, Sashima T, Miyashita K. Suppressive effect of neoxanthin on the differentiation of 3T3-L1 adipose cells. J Oleo Sci. (2008) 57:345-51. doi: 10.5650/jos.57.345

48. Friedman M, Levin CE. Chapter 7: Glycoalkaloids and calystegine alkaloids in potatoes. In: Singh J, Kaur L, editors. Advances in Potato Chemistry and Technology, 2nd ed. San Diego, CA: Academic Press (2016). p. 167-94. doi: 10.1016/B978-0-12-800002-1.00007-8

49. Lee K-R, Kozukue N, Han J-S, Park J-H, Chang E-y, Baek E-J, et al. Glycoalkaloids and metabolites inhibit the growth of human colon (HT29) and liver (HepG2) cancer cells. J Agric Food Chem. (2004) 52:2832-9. doi: 10.1021/jf030526d

50. Friedman M, Lee K-R, Kim H-J, Lee I-S, Kozukue N. Anticarcinogenic effects of glycoalkaloids from potatoes against human cervical, liver, lymphoma, and stomach cancer cells. J Agric Food Chem. (2005) 53:6162-9. doi: 10.1021/jf050620p

51. Friedman M. Chemistry and anticarcinogenic mechanisms of glycoalkaloids produced by eggplants, potatoes, and tomatoes. J Agric Food Chem. (2015) 63:3323-37. doi: 10.1021/acs.jafc.5b00818

52. Friedman M, Fitch T, Yokoyama W. Lowering of plasma LDL cholesterol in hamsters by the tomato glycoalkaloid tomatine. Food Chem. Toxicol. (2000) 38:549-53. doi: 10.1016/S0278-6915(00)00050-8 
53. Gao S-Y, Wang Q-J, Ji Y-B. Effect of solanine on the membrane potential of mitochondria in HepG2 cells and $\left[\mathrm{Ca}^{2+}\right] \mathrm{i}$ in the cells. World J Gastroenterol. (2006) 12:3359. doi: 10.3748/wjg.v12.i21.3359

54. Burlingame B, Mouille B, Charrondiere R. Nutrients, bioactive non-nutrients and anti-nutrients in potatoes. J Food Compos Anal. (2009) 22:494-502. doi: 10.1016/j.jfca.2009.09.001

55. Heuberger AL, Lewis MR, Chen M-H, Brick MA, Leach JE, Ryan EP. Metabolomic and functional genomic analyses reveal varietal differences in bioactive compounds of cooked rice. PLoS ONE (2010) 5:e12915. doi: 10.1371/journal.pone.0012915

56. Schauer N, Semel Y, Roessner U, Gur A, Balbo I, Carrari F, et al. Comprehensive metabolic profiling and phenotyping of interspecific introgression lines for tomato improvement. Nat Biotechnol. (2006) 24:44754. doi: $10.1038 /$ nbt1192

57. Valiñas MA, Lanteri ML, ten Have A, Andreu AB. Chlorogenic acid biosynthesis appears linked with suberin production in potato tuber (Solanum tuberosum). J Agric Food Chem. (2015) 63:4902-13. doi: $10.1021 /$ jf505777p

58. Zhang H, Yang B, Liu J, Guo D, Hou J, Chen S, et al. Analysis of structural genes and key transcription factors related to anthocyanin biosynthesis in potato tubers. Sci Horticult. (2017) 225:310-6. doi: $10.1016 /$ j.scienta.2017.07.018

59. Andre CM, Ghislain M, Bertin P, Oufir M, del Rosario Herrera M, Hoffmann L, et al. Andean potato cultivars (Solanum tuberosum L.) as a source of antioxidant and mineral micronutrients. J Agric Food Chem. (2007) 55:36678. doi: 10.1021/jf062740i

60. Navarre DA, Pillai SS, Shakya R, Holden MJ. HPLC profiling of phenolics in diverse potato genotypes. Food Chem. (2011) 127:34-41. doi: 10.1016/j.foodchem.2010.12.080

61. Reddivari L, Hale AL, Miller JC. Genotype, location, and year influence antioxidant activity, carotenoid content, phenolic content, and composition in specialty potatoes. J Agric Food Chem. (2007) 55:8073-9. doi: $10.1021 /$ jf071543w

62. Cajka T, Fiehn O. Toward merging untargeted and targeted methods in mass spectrometry-based metabolomics and lipidomics. Anal Chem. (2015) 88:524-45. doi: 10.1021/acs.analchem.5b04491

63. Salt DE, Baxter I, Lahner B. Ionomics and the study of the plant ionome. Annu Rev Plant Biol. (2008) 59:709-33. doi: 10.1146/annurev.arplant.59.032607.092942

64. McGhie TK, Rowan DD. Metabolomics for measuring phytochemicals, and assessing human and animal responses to phytochemicals, in food science. Mol Nutr Food Res. (2012) 56:147-58. doi: 10.1002/mnfr.201100545

65. Brennan L. Metabolomics in Nutrition Research: Current Status and Perspectives. London: Portland Press Limited (2013).

66. Claus SP. Development of personalized functional foods needs metabolic profiling. Curr Opin Clin Nutr Metab Care (2014) 17:567-73. doi: 10.1097/MCO.0000000000000107

67. Rodríguez-Burruezo A, Prohens J, Raigón M, Nuez F. Variation for bioactive compounds in ají (Capsicum baccatum L.) and rocoto (C. pubescens R. \& P.) and implications for breeding. Euphytica (2009) 170:169-81. doi: 10.1007/s10681-009-9916-5

68. Watanabe T, Maejima E, Yoshimura T, Urayama M, Yamauchi A, Owadano $\mathrm{M}$, et al. The ionomic study of vegetable crops. PLOS ONE (2016) 11:e0160273. doi: 10.1371/journal.pone.0160273

69. Ward JL, Poutanen K, Gebruers K, Piironen V, Lampi A-M, Nyström L, et al. The HEALTHGRAIN cereal diversity screen: concept, results, and prospects. J Agric Food Chem. (2008) 56:9699-709. doi: 10.1021/jf8009574

70. Huang Y, Tong C, Xu F, Chen Y, Zhang C, Bao J. Variation in mineral elements in grains of 20 brown rice accessions in two environments. Food Chem. (2016) 192:873-8. doi: 10.1016/j.foodchem.2015.07.087

71. Baxter IR, Ziegler G, Lahner B, Mickelbart MV, Foley R, Danku J, et al. Single-kernel ionomic profiles are highly heritable indicators of genetic and environmental influences on elemental accumulation in maize grain (Zea mays). PLOS ONE (2014) 9:e87628. doi: 10.1371/journal.pone.0087628

72. Asaro A, Ziegler G, Ziyomo C, Hoekenga OA, Dilkes BP, Baxter I. The interaction of genotype and environment determines variation in the maize kernel ionome. G3 (2016) 6:4175-83. doi: 10.1534/g3.116.034827
73. Ziegler G, Terauchi A, Becker A, Armstrong P, Hudson K, Baxter I. Ionomic screening of field-grown soybean identifies mutants with altered seed elemental composition. Plant Genome (2013) 6:1-9. doi: 10.3835/plantgenome2012.07.0012

74. Shakoor N, Ziegler G, Dilkes BP, Brenton Z, Boyles R, Connolly EL, et al. Integration of experiments across diverse environments identifies the genetic determinants of variation in Sorghum bicolor seed element composition. Plant Physiol. (2016) 170:1989-98. doi: 10.1104/pp.15.01971

75. Furrer AN, Chegeni M, Ferruzzi, MG. Impact of potato processing on nutrients, phytochemical, and human health. Crit Rev Food Sci Nutr. (2018) 58:146-58. doi: 10.1080/10408398.2016.1139542

76. Giavalisco P, Li Y, Matthes A, Eckhardt A, Hubberten HM, Hesse $\mathrm{H}$, et al. Elemental formula annotation of polar and lipophilic metabolites using $13 \mathrm{C}, 15 \mathrm{~N}$ and $34 \mathrm{~S}$ isotope labelling, in combination with high-resolution mass spectrometry. Plant J. (2011) 68:364-76. doi: 10.1111/j.1365-313X.2011.04682.x

77. Broeckling CD, Prenni JE. Stacked injections of biphasic extractions for improved metabolomic coverage and sample throughput. Anal Chem. (2017) 90:1147-53. doi: 10.1021/acs.analchem.7b03654

78. Turner MF, Heuberger AL, Kirkwood JS, Collins CC, Wolfrum EJ, Broeckling $C D$, et al. Non-targeted metabolomics in diverse sorghum breeding lines indicates primary and secondary metabolite profiles are associated with plant biomass accumulation and photosynthesis. Front Plant Sci. (2016) 7:953. doi: 10.3389/fpls.2016.00953

79. Smith CA, Want EJ, O’Maille G, Abagyan R, Siuzdak G. XCMS: Processing mass spectrometry data for metabolite profiling using nonlinear peak alignment, matching, and identification. Anal Chem. (2006) 78:779-87. doi: $10.1021 /$ ac051437y

80. Mahieu NG, Genenbacher JL, Patti GJ. A roadmap for the XCMS family of software solutions in metabolomics. Curr Opin Chem Biol. (2016) 30:87-93. doi: 10.1016/j.cbpa.2015.11.009

81. R Core Team. R: A Language and Environment for Statistical Computing. Vienna: R Foundation for Statistical Computing (2015).

82. Webb RE, Wilson DR, Shumaker JR, Graves B, Henninger MR, Watts J, et al. Atlantic: a new potato variety with high solids, good processing quality, and resistance to pests. Am Potato J. (1978) 55:141-5. doi: 10.1007/bf02852087

83. Zitnak A, Johnston GR. Glycoalkaloid content of B5141-6 potatoes. Am Potato J. (1970) 47:256-60. doi: 10.1007/bf02864825

84. Johnston G, Rowberry R. Yukon Gold: a new yellow-fleshed, medium-early, high quality table and french-fry cultivar. Am Potato J. (1981) 58:241-4. doi: 10.1007/BF02853905

85. Broeckling CD, Afsar FA, Neumann S, Ben-Hur A, Prenni JE. RAMClust: a novel feature clustering method enables spectral-matching-based annotation for metabolomics data. Anal Chem. (2014) 86:6812-7. doi: $10.1021 /$ ac501530d

86. Broeckling CD, Ganna A, Layer M, Brown K, Sutton B, Ingelsson E, et al. Enabling Efficient and confident annotation of LC-MS metabolomics data through ms1 spectrum and time prediction. Anal. Chem. (2016) 88:9226-34. doi: 10.1021/acs.analchem.6b02479

87. Hummel J, Strehmel N, Bölling C, Schmidt S, Walther D, Kopka J. Mass Spectral search and analysis using the golm metabolome database. In: Weckwerth W, Kahl G, editors. The Handbook of Plant Metabolomics. Berlin; Heidelberg: Wiley-VCH Verlag GmbH \& Co. KGaA (2013). p. 321-43. doi: $10.1002 / 9783527669882 . c h 18$

88. Hummel J, Selbig J, Walther D, Kopka J. The golm metabolome database: a database for GC-MS based metabolite profiling. In: Nielsen J, Jewett MC, editors. Metabolomics: A Powerful Tool in Systems Biology. Berlin; Heidelberg: Springer Berlin Heidelberg (2007). p. 75-95.

89. Fahy E, Sud M, Cotter D, Subramaniam S. LIPID MAPS online tools for lipid research. Nucl Acids Res. (2007) 35(Suppl. 2):W606-12. doi: 10.1093/nar/gkm324

90. Wishart DS, Jewison T, Guo AC, Wilson M, Knox C, Liu Y, et al. HMDB 3.0-The Human Metabolome Database in 2013. Nucl Acids Res. (2012) 41:D801-7. doi: 10.1093/nar/gks1065

91. Sumner L, Amberg A, Barrett D, Beale M, Beger R, Daykin C, et al. Proposed minimum reporting standards for chemical analysis. Metabolomics (2007) 3:211-21. doi: 10.1007/s11306-007-0082-2 
92. Haugen J-E, Tomic O, Kvaal K. A calibration method for handling the temporal drift of solid state gas-sensors. Anal Chim Acta (2000) 407:23-39. doi: 10.1016/S0003-2670(99)00784-9

93. Broccardo CJ, Schauer KL, Kohrt WM, Schwartz RS, Murphy JP, Prenni JE. Multiplexed analysis of steroid hormones in human serum using novel microflow tile technology and LC-MS/MS. J Chromatogr B (2013) 934:1621. doi: 10.1016/j.jchromb.2013.06.031

94. Shrivastava A, Gupta V. Methods for the determination of limit of detection and limit of quantitation of the analytical methods. Chron Young Sci. (2011) 2:21-5. doi: 10.4103/2229-5186.79345

95. Becker K, Kaus S, Krause C, Lepom P, Schulz C, Seiwert M, et al. German Environmental Survey 1998 (GerES III): environmental pollutants in blood of the German population. Int J Hyg Environ Health (2002) 205:297-308. doi: 10.1078/1438-4639-00155

96. Benjamini Y, Hochberg Y. Controlling the false discovery rate: a practical and powerful approach to multiple testing. J R Stat Soc B Methodol. (1995) 57:289-300.

97. Warnes GR, Bolker B, Bonebakker L, Gentleman R, Huber W, Liaw A, et al. gplots: Various R Programming Tools for Plotting Data. R package version 3.0.1 (2016). Available online at: https://CRAN.R-project.org/package= gplots

98. Kultti A, Pasonen-Seppänen S, Jauhiainen M, Rilla KJ, Kärnä R, Pyöriä E, et al. 4-Methylumbelliferone inhibits hyaluronan synthesis by depletion of cellular UDP-glucuronic acid and downregulation of hyaluronan synthase 2 and 3. Exp Cell Res. (2009) 315:1914-23. doi: 10.1016/j.yexcr.2009.03.002

99. Lin JP, Yang JS, Lin JJ, Lai KC, Lu HF, Ma CY, et al. Rutin inhibits human leukemia tumor growth in a murine xenograft model in vivo. Environ Toxicol. (2012) 27:480-4. doi: 10.1002/tox.20662

100. Lu M-K, Shih Y-W, Chien T-TC, Fang L-H, Huang H-C, Chen P-S. $\alpha$-Solanine inhibits human melanoma cell migration and invasion by reducing matrix metalloproteinase-2/9 activities. Biol Pharmaceut Bull. (2010) 33:1685-91. doi: 10.1248/bpb.33.1685

101. Liu IM, Hsu FL, Chen CF, Cheng JT. Antihyperglycemic action of isoferulic acid in streptozotocin-induced diabetic rats. Br J Pharmacol. (2000) 129:6316. doi: 10.1038/sj.bjp.0703082

102. Wang G-F, Shi L-P, Ren Y-D, Liu Q-F, Liu H-F, Zhang R-J, et al. Anti-hepatitis $\mathrm{B}$ virus activity of chlorogenic acid, quinic acid and caffeic acid in vivo and in vitro. Antivir Res. (2009) 83:186-90. doi: 10.1016/j.antiviral.2009.05.002

103. Roberts RL, Green J, Lewis B. Lutein and zeaxanthin in eye and skin health. Clin Dermatol. (2009) 27:195-201. doi: 10.1016/j.clindermatol.2008.01.011

104. Mares-Perlman JA, Millen AE, Ficek TL, Hankinson SE. The body of evidence to support a protective role for lutein and zeaxanthin in delaying chronic disease. Overview. J Nutr. (2002) 132:518S-24S. doi: $10.1093 / \mathrm{jn} / 132.3 .518 \mathrm{~S}$

105. Connor WE. $\alpha$-Linolenic acid in health and disease. Am J Clin Nutr. (1999) 69:827-8. doi: 10.1093/ajcn/69.5.827

106. Sano M, Ernesto C, Thomas RG, Klauber MR, Schafer K, Grundman $\mathrm{M}$, et al. A controlled trial of selegiline, alpha-tocopherol, or both as treatment for Alzheimer's disease. New England J Med. (1997) 336:1216-22. doi: 10.1056/NEJM199704243361704

107. Bieri JG, Evarts RP. Gamma tocopherol: metabolism, biological activity and significance in human vitamin E nutrition. Am J Clin Nutr. (1974) 27:980-6. doi: 10.1093/ajcn/1.3.200

108. Tahiliani AG, Beinlich CJ. Pantothenic acid in health and disease. Vitam Horm. (1991) 46:165-228. doi: 10.1016/S0083-6729(08)60684-6

109. Morris MS, Picciano MF, Jacques PF, Selhub J. Plasma pyridoxal 5' phosphate in the US population: the National Health and Nutrition Examination Survey, 2003-2004. Am J Clin Nutr. (2008) 87:1446-54. doi: $10.1093 / \mathrm{ajcn} / 87.5 .1446$

110. Snyderman SE, HOLT LE, CARRETERO R, Jacobs K. Pyridoxine deficiency in the human infant. Am J Clin Nutr. (1953) 1:200-7.

111. Wei T, Simko V. corrplot: Visualization of a Correlation Matrix. R package version 0.77. (2016). Available online at: https:/CRAN.R-project. org $/$ package $=$ corrplot
112. Lu W, Haynes K, Wiley E, Clevidence B. Carotenoid content and color in diploid potatoes. J Am Soc Horticult Sci. (2001) 126:722-6.

113. Iwanzik W, Tevini M, Stute R, Hilbert R. Carotinoidgehalt undzusammensetzung verschiedener deutscher Kartoffelsorten und deren Bedeutung für die Fleischfarbe der Knolle. Potato Res. (1983) 26:149-62. doi: 10.1007/BF02357477

114. Brown C. Antioxidants in potato. Am J Pot Res. (2005) 82:163-72. doi: 10.1007/BF02853654

115. Brown C, Edwards C, Yang C-P, Dean B. Orange flesh trait in potato: inheritance and carotenoid content. J Am Soc Hort Sci. (1993) 118:145-50.

116. Roessner U, Wagner C, Kopka J, Trethewey RN, Willmitzer L. Simultaneous analysis of metabolites in potato tuber by gas chromatography-mass spectrometry. Plant J. (2000) 23:131-42. doi: 10.1046/j.1365-313x.2000.00774.x

117. Enot DP, Beckmann M, Draper J. Detecting a difference-assessing generalisability when modelling metabolome fingerprint data in longer term studies of genetically modified plants. Metabolomics (2007) 3:335-47. doi: 10.1007/s11306-007-0064-4

118. Asano N, Nash RJ, Molyneux RJ, Fleet GW. Sugar-mimic glycosidase inhibitors: natural occurrence, biological activity and prospects for therapeutic application. Tetrahedron (2000) 11:1645-80. doi: 10.1016/S0957-4166(00)00113-0

119. Friedman M. Potato glycoalkaloids and metabolites: roles in the plant and in the diet. J Agric Food Chem. (2006) 54:8655-81. doi: 10.1021/jf061471t

120. Ginzberg I, Tokuhisa JG, Veilleux RE. Potato steroidal glycoalkaloids: biosynthesis and genetic manipulation. Potato Res. (2009) 52:1-15. doi: 10.1007/s11540-008-9103-4

121. Johns T, Alonso JG. Glycoalkaloid change during the domestication of the potato, Solanum Section Petota. Euphytica (1990) 50:203-10. doi: 10.1007/BF00023646

122. Korpan YI, Nazarenko EA, Skryshevskaya IV, Martelet C, Jaffrezic-Renault N, Anna V. Potato glycoalkaloids: true safety or false sense of security? Trends Biotechnol. (2004) 22:147-51. doi: 10.1016/j.tibtech.2004.01.009

123. Navarre DA, Goyer A, Shakya R. Developing the nutritional potential of potato. Food (2009) 3:118-24.

124. Juhász Z, Dancs G, Marincs F, Vossen M, Allefs S, Bánfalvi Z. Vitamin C, B5, and B6 contents of segregating potato populations detected by GC-MS: a method facilitating breeding potatoes with improved vitamin content. Plant Breed. (2014) 133:515-20. doi: 10.1111/pbr. 12169

125. Valiñas MA, Lanteri ML, ten Have A, Andreu AB. Chlorogenic acid, anthocyanin and flavan-3-ol biosynthesis in flesh and skin of Andean potato tubers (Solanum tuberosum subsp. andigena). Food Chem. (2017) 229:83746. doi: 10.1016/j.foodchem.2017.02.150

126. Subramanian NK, White PJ, Broadley MR, Ramsay G. Variation in tuber mineral concentrations among accessions of Solanum species held in the Commonwealth Potato Collection. Genet Resour Crop Evol. (2017) 64:192735. doi: 10.1007/s10722-016-0483-z

127. Paget M, Amoros W, Salas E, Eyzaguirre R, Alspach P, Apiolaza L, et al. Genetic evaluation of micronutrient traits in diploid potato from a base population of Andean Landrace Cultivars. Crop Sci. (2014) 54:1949-59. doi: $10.2135 /$ cropsci2013.12.0809

Conflict of Interest Statement: The authors declare that the research was conducted in the absence of any commercial or financial relationships that could be construed as a potential conflict of interest.

Copyright (C) 2018 Chaparro, Holm, Broeckling, Prenni and Heuberger. This is an open-access article distributed under the terms of the Creative Commons Attribution License (CC BY). The use, distribution or reproduction in other forums is permitted, provided the original author(s) and the copyright owner are credited and that the original publication in this journal is cited, in accordance with accepted academic practice. No use, distribution or reproduction is permitted which does not comply with these terms. 